\title{
Wurzen
}

\section{Wechselvolle Geschichte einer sächsischen Kleinstadt}

\section{Wolfgang Ebert}

\section{Von der Besiedlung zur Siedlung: die Vor- und Frühgeschichte der Stadtflur}

Nachdem das Eis der letzten Eiszeit geschmolzen war, die Mulde ihren heutigen Weg nach Norden eingeschlagen und sich in die von Eis und Schmelzwasser zurückgelassenen Moränenplatten einzuschneiden begonnen hatte, nahm auch an den jetzt neu entstandenen Hochufern des Flusses die Geschichte der Menschen ihren Anfang. Das war etwa vor 11.000 Jahren. Schweifende altsteinzeitliche Jäger suchten besonders die aufragenden Porphyrkuppen über der Kältesteppe am Rand der Muldenaue und der Hohburger Berge auf. Dort hinterließen sie ihre Spuren, zum Beispiel am Zinkenberg bei Hohburg. ${ }^{1}$

Aus dem Mesolithikum nimmt die Funddichte von Werkzeugen und Spuren menschlicher Tätigkeit zu; und mit dem Übergang zum Ackerbau zu Ende des Neolithikums wurden die Menschen am Ostufer der Mulde auf Dauer sesshaft. Die 1997/98 durchgeführten Ausgrabungen durch Mitarbeiter des Landesamtes für Archäologie westlich der einstigen Posthalterei am Crostigall brachten es zutage: Seit 6.000 Jahren - seit der Jungsteinzeit- siedeln Menschen oberhalb von Muldenaue und Rietzschketal. In der Bronzezeit trug die Terrasse oberhalb der Aue zwischen Wurzen (Crostigall), Roitzsch (Heidenberg) und Dehnitz gleich mehrere Siedlungen, auch einige Begräbnisplätze.

Um etwa 450 v. Chr. befand sich eine erste germanische Siedlung am Hang zur Aue, etwa auf dem Gelände der heutigen Filzfabrik. Der germanische Kultureinfluss blieb bis in spätrömische Zeit bestehen. Die Völkerwanderung dünnte die Besiedlung an den Ufern der Mulde aus.

\section{„altera regio Neletici ubi est vurcine civitas“. Wie Wurzen ins Licht der Geschichte trat}

„Die andere Landschaft Neletici, wo sich der befestigte Ort Wurzen befindet", übergab neben einigen anderen Gebieten und Orten ( $\mathrm{z}$. B. Halle, Eilenburg, Bernburg) am 29. Juli 961 der deutsche König Otto I. dem St.-MoritzKloster in Magdeburg zur Einziehung des Kirchenzehnten. ${ }^{2}$ Die Urkunde, die der König in Ohrdruf über diese Schenkung ausfertigen ließ, enthält zum ersten Mal den Namen des Ortes. Aber „Vurcine“ war zu diesem Zeitpunkt noch keine Stadt; "civitas" bedeutete eher „befestigter Ort“ oder „Burgward“. Wichtig für uns jedoch ist, dass die Ansiedlung noch einiges älter sein muss.

Der überlieferte Ortsname ist aus dem Altsorbischen herzuleiten. Schöttgen meinte, die Bedeutung "am Fluss" (gemeint ist die zwischen Burgberg und Crostigall fließende Rietzschke) zu erkennen ${ }^{3}$. Seit dem 19. Jahrhundert nimmt man aber doch eher eine Ableitung von einem Personennamen Vorč oder Vorz (zu vorčeti „knurren“) an. ${ }^{4}$

$\mathrm{Ab}$ dem 7. Jahrhundert wird die slawische Landnahme Mulde aufwärts auch unsere, in der Völkerwanderung stark entsiedelte Gegend erreicht haben. Am hochwassersicheren rechten Mulde-Ufer in der Nähe der RietzschkeMündung, wo auch germanische Siedlungsspuren nachzuweisen sind, ist mit slawischen Siedlungen $\mathrm{zu}$ rechnen. Eine befestigte Siedlung hat ganz bestimmt auf der Spornlage der späteren Domfreiheit (heute Domplatz) gelegen, noch früher sicher eine auf dem Crostigall und ein Fischerdorf im Rietzschketal dazwischen. ${ }^{5}$ Diese Punkte waren nicht nur siedlungsgünstig (geschützte Lage, Wasserquellen), sondern sie wurden auch strategisch zunehmend bedeutungsvoller. Hier querte ein uralter Handelsweg (die „Hohe Straße“ oder „Via 


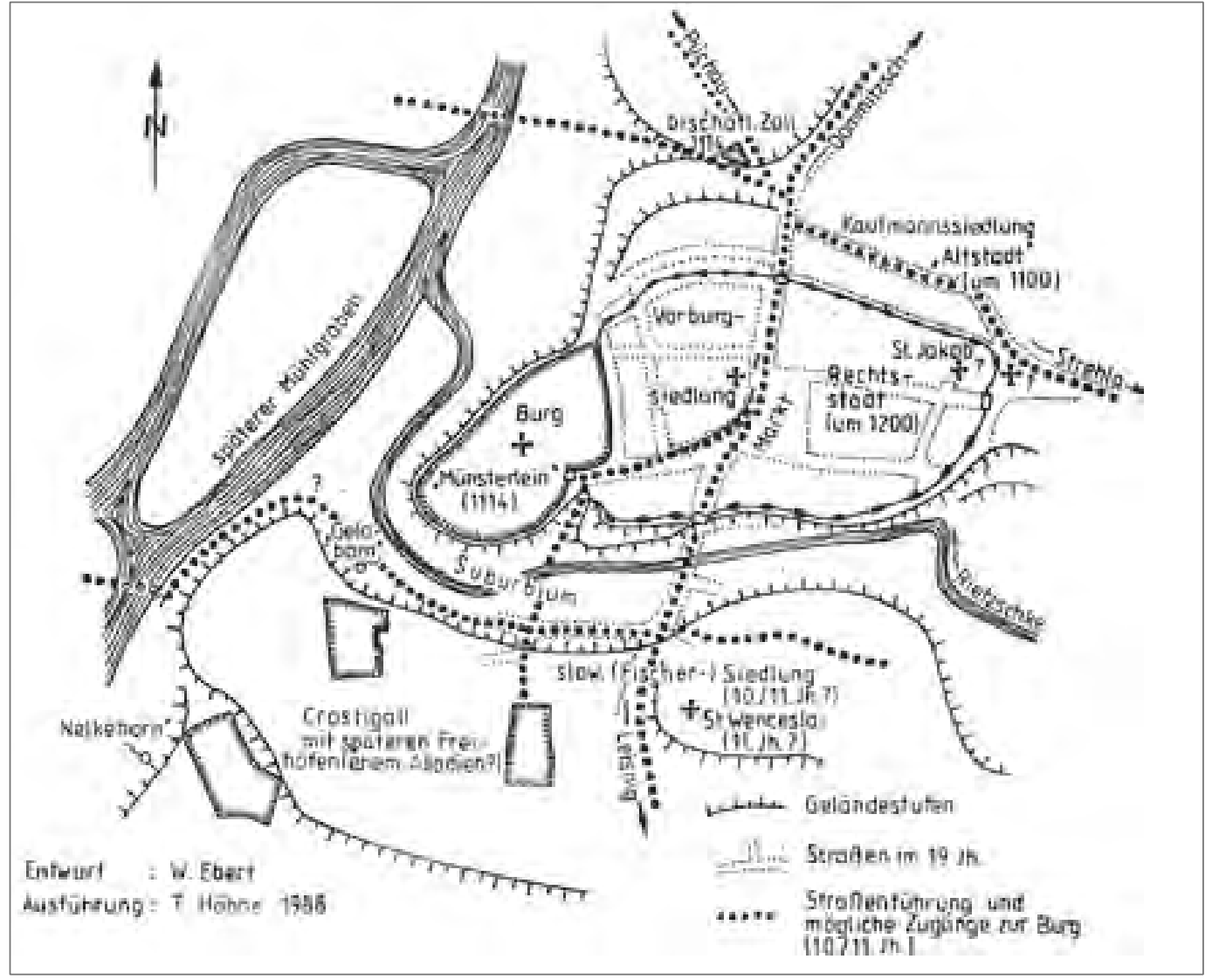

regia") die Mulde in einer Furt von West nach Ost, und am rechten Hochufer führte eine der Salzstraßen von Norden nach Süden. Beide kreuzten sich im heutigen Stadtgebiet (Gerhart-Hauptmann-Platz/Albert-Kuntz-Straße/ Altstadt). ${ }^{6}$

Es ist also verständlich, warum sich deutsche Feudalgewalten seit Beginn ihres Übergreifens ins slawische Siedelgebiet zwischen Saale und Elbe unter Heinrich I. auch dieses Punktes an der Mulde bemächtigten, denn von hier ließen sich die Verbindungswege zur weit nach Osten vorgeschobenen, bereits 929 gegründeten Burg Meißen sichern. Der an der Mulde installierte Burgward diente nicht nur der Behauptung des wichtigen Mulde-Übergangs, sondern darüber hinaus der Königsherrschaft über die unterworfenen slawischen Stämme und als einer der Ansatzpunkte für die später einsetzende deutsche Besiedlung des Landes (Landesausbau). Damit einher ging die verstärkte Christianisierung der noch heidnischen Sorben. Heinrichs Sohn und Nachfolger Otto I. nutzte die Institutionen und die Machtmittel der Kirche bewusst für die Stärkung seiner Königsmacht und für die imperialen Ambitionen seiner Dynastie. Als er im Juli 961 in Ohrdruf die besagte Schenkungsurkunde ausfertigen ließ, befand er sich bereits auf dem Weg nach Rom zur Kaiserkrönung. Zuwendungen und Zugeständnisse an Kirche und Papst sollten seine Krönung vorbereiten und begünstigen, aber auch seinen Plan, in Magdeburg ein Erzbistum und damit ein weit nach Osten wirkendes Machtzentrum des jungen deutschen Staates zu schaffen, dem auch das 968 neu gegründete Bistum Meißen zugeordnet wurde. In diesem Zusammenhang muss man die Zuweisung des Zehnten unter anderem aus der „Landschaft der Neletitzer" ${ }^{\text {"7 }}$ an ein Kloster in Magdeburg vor mehr als tausend Jahren sehen.

Die Lage Wurzens an einem früh genutzten und wichtigen Mulde-Übergang im Verlauf einer vielbenutzten West-Ost-Straße erklärt einmal seine frühe Nennung, auch weitere Erwähnungen im Zusammenhang mit kriegerischen Ereignissen im 11. Jahrhundert: Thietmar von Merseburg berichtet für 1017 über die Nutzung der Wurzener Mulde-Furt durch die mit Kaiser Heinrich II. gegen die Polen verbündeten Liutitzen ${ }^{8}$. Die Annalen des Klosters Pegau vermelden für 1080, dass Herzog Vratislav von Böhmen dem bedrängten deutschen König Heinrich IV. im Krieg gegen die Fürstenopposition Waffenhilfe leistete und vor der Schlacht bei Hohenmölsen (15.10.1080) die Mulde bei Wurzen überquerte und „das Land bis Leipzig verheerte"
Siedlungskerne und Stadtentwicklung in Wurzen
6 Schöttgen 1717 , S. 14-15, berichtet, eine „wüste Hoff-Stadt“ habe vor Zeiten hier gelegen. Die Nachricht könnte sich auf die 1114 genannte bischöfliche "Zollstation" beziehen. Zum Straßenkreuz nö. der Wurzener Burg vgl. Walter Schlesinger, Handbuch der historischen Stätten Deutschlands. Band 8 (Sachsen), Stuttgart 1965, S. 305.

7 An den alten Landschaftsnamen erinnerte bis ins 19. Jahrhundert die „Netlicke“ oder der "Nelkeborn“ unterhalb des Steinhofs auf dem Gelände der heutigen Filzfabrik. Vgl. Schöttgen 1717, S. 6-7.

8 Chronicon, a.a.O., S. 425. Bei dieser Gelegenheit erhalten wir auch erstmals Kenntnis von einem Hochwasser der Mulde.

9 Annales Pegavienses et Bosovienses. In: Monumenta Historica Germaniae. Scriptores, Bd. 16 hrsg. von Georg Heinrich Pertz, Hannover 1859, S. 241. 


\section{Unter der Herrschaft des Krumm- stabes. Vom Burgward zur Rechtsstadt und Bischofsresidenz}

In dem seit 1465 belegten Wappen der Stadt ist ein gerüsteter, aber unbewaffneter, nach links hin sprengender Reiter zu sehen, ein Geharnischter, der in seiner rechten Hand einen Krummstab führt. ${ }^{10}$ Vermutlich sollte ursprünglich der Reiter den heiligen Wenzel darstellen, den Patron der Stadtkirche; und der Krummstab wäre dann ursprünglich die Lanze des Heiligen gewesen. Das Zeichen bischöflicher Würde kam somit erst nachträglich in das Wappen und soll an die Zeit erinnern, als die Bischöfe von Meißen die Herren der Stadt und der dazugehörigen „terra Worczynensis“ waren. Um das Jahr 1000 wurde im Umfeld der Meißner Bischöfe eine Urkunde Kaiser Ottos III. manipuliert, der zufolge sie bereits 995 in den weltlichen Besitz unter anderem des Burgwards Wurzen gelangt sein wollen. ${ }^{11}$ Aber gerade die offensichtliche Fälschung zeigt, dass der Besitz so sicher nicht gewesen sein dürfte. Die Bischöfe mussten in den folgenden 200 Jahren mehrmals den Ort und die umliegende Landschaft energisch behaupten, so gegen ihre Merseburger Amtsbrüder (1017 machte Kaiser Heinrich II. die Mulde zur Grenze zwischen den Bistümern Meißen und Merseburg ${ }^{12}$ ) und auch gegen die wettinischen Markgrafen von
Meißen. Sie taten das, indem sie an der Mulde Tatsachen schufen, die eine stärkere rechtliche und geistliche Bindung der Landschaft und ihrer Bewohner an das Bistum bewirkten. Um die Missionsarbeit in unserem Gebiet zu verbessern, gründete 1114 Bischof Herwig (1106-1119) in Wurzen ein Kollegiatstift ${ }^{13}$, zu dem auch eine romanische Pfeilerbasilika gehörte. ${ }^{14}$

Vor allem aber wurden Bauern aus den westlichen Reichsgebieten ins Land geholt, die sich in bereits vorhandenen Dörfern niederließen oder auf Rodungsland neue Dörfer gründeten und besiedelten. Dieser Vorgang ist bei Kühren (seit 2006 ein Stadtteil von Wurzen) für das Jahr 1154 mit der Ansiedlung von flämischen Siedlerfamilien durch Bischof Gerung (1152-1170) urkundlich belegt. ${ }^{15}$ Auf der Wurzener Burg verwaltete ein bischöflicher Vogt die umliegenden Orte. Wurzen selbst nahm an Umfang zu: Zwischen Burgberg und der späteren Färbergasse ist für diese Zeit eine Dienstmannensiedlung anzunehmen; nordöstlich der Burg war seit etwa 1100 eine Handwerker- und Kaufmannssiedlung („Altstadt“) entstanden, zu der die Jacobskirche und ein dreieckiger Markt (Jacobsplatz) gehörten. Sicher schon um diese Zeit wurde östlich der Burg und einer bereits vorhandenen Vorburgsiedlung zwischen den bestehenden Siedlungskernen um einen rechteckigen Markt eine Siedlung angelegt, ummauert und mit Stadtrechten versehen. ${ }^{16}$
Blick von der Wenceslaikirche auf Dom und Bischofsschloss Foto: Wolfgang Ebert

10 Heinz Göschel (Hrsg.), Lexikon Städte und Wappen der Deutschen Demokratischen Republik, Leipzig 1984; Karlheinz Blaschke, Unsere Stadtwappen. In: „Der Rundblick“ 1/1980, S. 32 f.; Heinz Machatschek, Unterhaltsame Wappenkunde, Berlin 1981, S. 135 f.

11 CDS I A 1, Nr. 43.

12 Thietmar von Merseburg, Chronicon. In: Ausgewählte Quellen zur deutschen Geschichte des Mittelalters (Freiherr vom Stein Gedächtnisausgabe Bd. IX), Darmstadt 1957, S. 413; CDS II 1, Nr. 21.

13 Leo Bönhoff, Die Stiftungsurkunde des Wurzener Kollegiatstiftes, In: Beiträge zur sächsischen Kirchengeschichte 37 (1914), S. 1-15; Text bei Schöttgen 1717, S. $85-89$.

14 Andrea Sandner, Dom St. Marien zu Wurzen, Beucha/ Markleeberg 2014, S. 8-11.

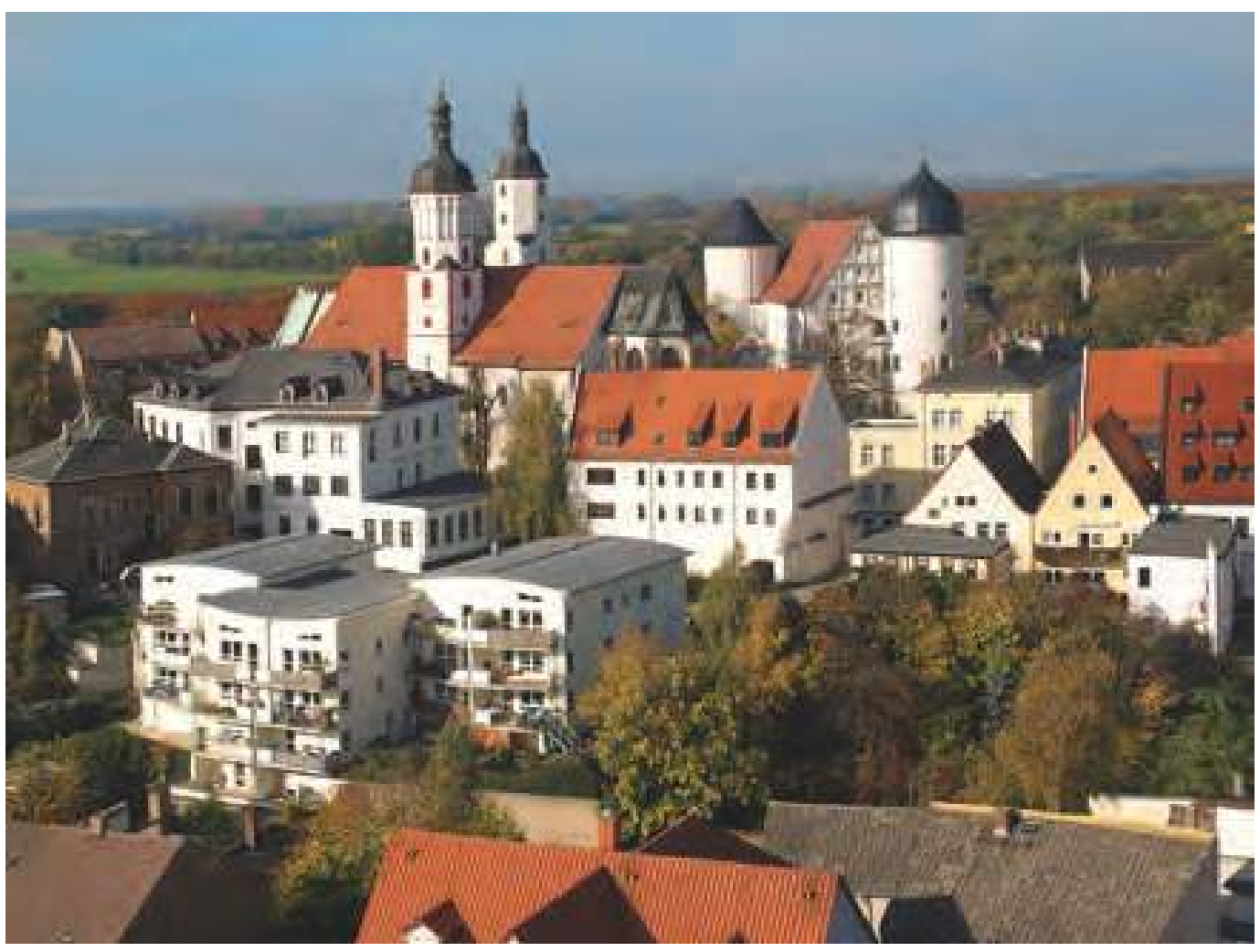


Seit 1252 wurden die Hoheitsrechte der Meißner Kirche im Wurzener Land wieder angefochten, diesmal vom Markgrafen von Meißen. 1284 sicherte dann ein Magdeburger Schiedsgericht den Bischöfen endgültig landesherrliche Befugnisse (die Gerichtsbarkeit) über Wurzen und das Wurzener Land zu. In der in Dresden darüber ausgefertigten Urkunde wurden zum ersten Mal die Grenzen des Wurzener Landes ziemlich genau beschrieben. ${ }^{17}$ Es erstreckte sich vor allem auf dem Ostufer der Mulde bis an die Wasserscheide zur Elbe, schloss aber auch das Gebiet des alten Burgwardes Püchau ${ }^{18}$ westlich der Mulde mit ein.

Der Umstand, dass die Bischöfe weitere 200 Jahre später zeitweilig ihren Sitz nach Wurzen verlegten, von 1491 bis 1497 auch das spätgotische Schloss erbauen ließen, Wurzen somit zu einem ihrer Residenzorte (neben Meißen, Nossen und Stolpen) machten, hat dem Ort einiges an kurzzeitiger politischer Bedeutung eingebracht, vor allem aber eine wirtschaftliche Aufstiegsphase beschert. An Mulde und Mühlgraben ließen die Bischöfe Mühlen anlegen. ${ }^{19}$ Die Stadt erlangte durch ihre Gewerbe - wie Brauerei, Leineweberei, Färberei, Bleicherei und das Bauhandwerk - Gewicht. Auch aus dem Fährbetrieb auf der Mulde, der Fischerei und der Bewirtschaftung der Stadtfelder wurden Einnahmen erzielt. Die „Anhäufung von Kapital “ ermöglichte kostspielige Bauten, vor allem unter Bischof Johann von Salhausen (Schloss, Dom, Wenceslaikirche, Rathaus), veranlasste die geistlichen Stadtherren aber auch zur Verpachtung bzw. zum Verkauf von Hoheitsrechten (z.B. der Gerichtsbarkeit) an den Rat der Stadt. Den Ideen der Reformation blieb man zunächst verschlossen. Kurfürst Johann Friedrich der Großmütige musste energisch nachhelfen. 1539 schickte er den ersten evangelischen Pfarrer an die Stadtkirche St. Wenceslai. ${ }^{20}$ Das war der Beginn der Reformation in Stadt und Stift Wurzen. Aber die Bischofszeit endete erst 1581.

\section{Pfaffenkrieg, Fladenkrieg, Saukrieg. Wurzen als Zankapfel geistlicher und weltlicher Gewalten}

Um 1300 war Wurzen das, was wir durchaus eine mittelalterliche Stadt nennen können: Es besaß einen Markt und Marktrecht ${ }^{21}$ sowie städtische Institutionen und Gewerbe. Für das Jahr 1347 wird zum ersten Mal ein Bürgermeister genannt: Heidenreich von Nischwitz. Gegenüber der ursprünglich vor allem militärischen Funktion als Burgward waren dem Ort auch überörtliche ökonomische und administrative Aufgaben zugewachsen. Es war aber noch ein umwehrter Platz im Schutze einer Burg. Das war auch nötig, denn nach dem Landesausbau durch die Bischöfe wurde das Wurzener Land zunehmend zum Objekt konkurrierender Mächte.

1381 entbrannte um seinen Besitz zwischen dem Erzbischof von Magdeburg und dem Bischof von Meißen der so genannte „Pfaffenkrieg“. Im Gegensatz zu früheren kriegerischen Ereignissen, die Wurzen berührten, ging es nunmehr um größere machtpolitische Erwägungen und Einflussnahme. Weil Bischof Nikolaus I. (1379-1392) die Unabhängigkeit des Bistums vom Magdeburger Erzstift anstrebte, fielen zweimal die „Söldlinge“ des Erzbischofs Ludwig von Meißen (eines Wettiners!) brandschatzend ins Wurzener und Mügelner Gebiet ein, wurden aber beide Male zurückgeschlagen. ${ }^{22}$ Schließlich kam es 1384 zu einem Schutzvertrag zwischen dem Bischof und dem Markgrafen, der dessen Nachfolgern künftig die Möglichkeit bot, landesherrliche Ambitionen der Bischöfe in Grenzen zu halten. ${ }^{23}$

Seiner militärischen Funktion scheint die Stadt bis ins 15. Jahrhundert noch gerecht geworden zu sein: Die Bischöfe blieben in ihrem Besitz. Auch die Hussiten unter Prokop richteten 1429/30 größeren Schaden offenbar nicht an. Zumindest wird uns nichts anderes berichtet. Gräben und Mauern waren damals noch zu unterhalten oder $\mathrm{zu}$ erweitern, wie das von 1413 bis 1512 noch mehrmals geschah. Die Entwicklung der Kriegstechnik im 16. Jahrhundert aber machte Städte wie Wurzen vollends hilflos und zum Spielball der politischen Gewalten.

Das zeigte sich bereits 1542 in der so genannten „Wurzener Fehde" ${ }^{\text {"24 }}$ zwischen dem Kurfür-sten Johann Friedrich und dem Herzog Moritz von Sachsen, denen damals gemeinsam die Schutzherrschaft über das Wurzener Land zustand. Anfang April waren die fürstlichen Vettern wegen Wurzen in Streit geraten, der bald kriegerische Ausmaße anzunehmen drohte. Der Kurfürst wollte dem Herzog bei einer möglichen Säkularisierung der bischöflichen Territorien zuvorkommen und hatte Wurzen unter dem Vorwand, die vom Bischof zurückgehaltene Türkensteuer einzutreiben, besetzt und zu befestigen begonnen. Die beiden Fürsten konnten noch einmal besänftigt und zum Frieden zurückgebracht werden, unter anderem durch Martin Luther, der bei dieser Gelegenheit bemerkte, Wurzen sei „der Unkost, so bereits draufgegangen ist ${ }^{\text {“ } 25}$, nicht wert. In der Bevölkerung ist diese unblutige Fehde als „Fladenkrieg“ in Erinnerung geblieben. Denn Ostern 1542 war sie zu Ende, Stadt
15 CDS 2, 01, Nr. 50. Umfassend dazu: Enno Bünz, Kühren 1154 Ostsiedlung und Landesausbau in Sachsen. In: Schriften zur sächsischen Geschichte und Volkskunde; Bd. 23, Leipzig 2008, S. $17 \mathrm{ff}$.

16 Der genaue Zeitpunkt ist nicht bekannt, kann aber für die Zeit 1150-1200 auf Grund jüngster archäologischer Befunde (2006) vermutet werden. Vgl. Anne Hohmann, Archäologische Ausgrabungen in Sachsen. Auf dem Marktplatz in Wurzen. (www.archaeologie.sachsen.de, abgerufen 15.12.2014).

17 CDS II 1, Nr. 50.

18 König Heinrich III. übereignete das ,castellum quod dicitur Bichni“ bereits am 20.7.1040 (CDS II 1, Nr. 22). Damit war die alte Mulde-Querung der Via Regia fest in der Hand des Hochstifts Meißen.

19 Schöttgen 1717, S. 515 f. Die früheste Erwähnung einer Mühle an der Mulde stammt von 1415 (CDS II, 2, Nr. 881).

20 Johann Hoffmann (1485-1559) aus Thammenhain wurde 1542 auf kurfürstlichen Befehl zum ersten „Superattendenten im Stifte, Amt und Stadt Wurzen verordnet“. Vgl. Julius Leopold Pasig, Kurze Geschichte der Reformation in der Stadt Wurzen, Wurzen 1839, S. 56; Theodor Franke, Die Parochie Wurzen. In: Neue Sächsische Kirchengalerie. Die Ephorie Grimma rechts der Mulde, Leipzig 1914, S. 67.

21 Erstmals wird Wurzen als Stadt bezeichnet 1413 in einer Urkunde Bischof Rudolfs von der Planitz (Schöttgen 1717, S.19).

22 Schöttgen 1717, S. 547-548, teilt nur das Ereignis mit. Eduard Machatschek (Geschichte der Bischöfe des Hochstifts Meissen, Dresden 1884, S. 327) macht detailliertere Angaben. Beide berufen sich aber auf Cyriacus Spangenberg (Mansfeldische Chronica, 1572, Cap. 297).

23 CDS I B, 1, Nr. 118; CDS II, 2 , Nr. 685.

24 Dr. Burkhardt, Die Wurzener Fehde. In: Archiv für die Sächsische Geschichte 4 (1866), S. 57-81.

25 Sendschreiben vom 7. April 1542 „An den Kurfürsten Johann Friedrich und den Herzog Moritz von Sachsen und deren Landstände“: In: Dr. Martin Luthers Briefe, Sendschreiben und Bedenken. Fünfter Theil, herausgegeben von Wilhelm Martin Leberecht de Wette: Berlin 1828, S. 456-461. 
Epitaph für Bischof Johann IX. von Haugwitz in der Stadtkirche in Mügeln Foto: Matthias Donath und Stift wurden evangelisch, der Bischof blieb Landesherr, das Domkapitel katholisch. Und die Wurzener und die Soldaten konnten noch einmal in Ruhe und Frieden ihren traditionellen Osterfladen (eine Art Eierkuchen) essen. ${ }^{26}$ Aber der Waffengang war nur aufgeschoben. Fünf Jahre später, während des Schmalkaldischen Krieges, plünderten kursächsische Reiter die Stadt und ermordeten den Bürgermeister Georg Herre. Die Wurzener hatten also allen Grund, wenn sie nach der Schlacht bei Mühlberg 1547 dem Sieger Moritz huldigten.

Aber auch die mit Moritz nunmehr zur Kurwürde gelangten Albertiner waren auf die Aneignung des Stiftsbesitzes aus. So sah Kurfürst August von Sachsen zunächst weg, als sein Stallmeister Hans von Carlowitz es wagte,

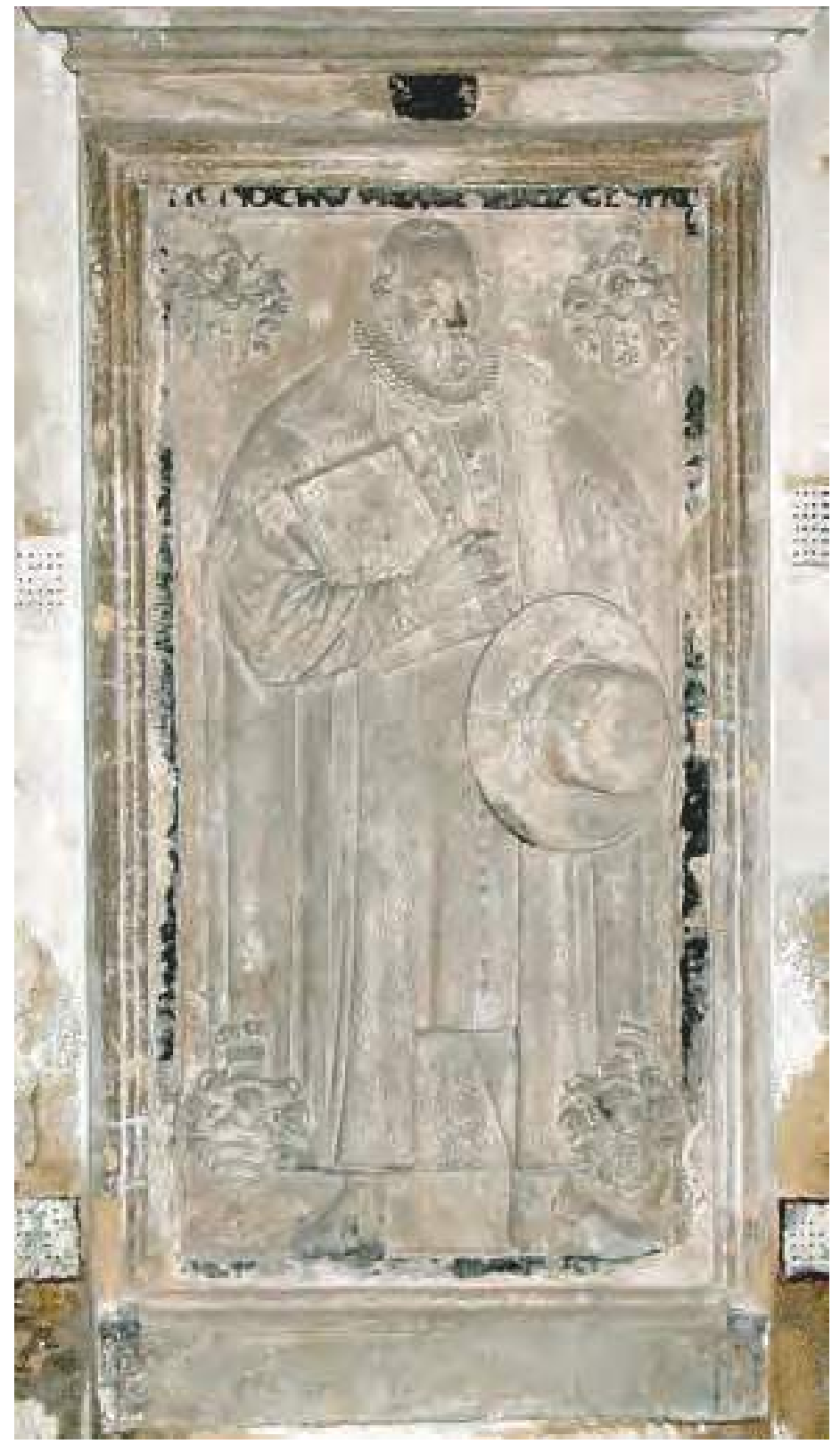

wegen eines Erbschaftsstreites eine Privatfehde gegen den Bischof Johann IX. von Haugwitz (1555-1581) vom Zaune zu brechen. ${ }^{27}$

Nachdem es den Carlowitz'schen Reitern mehrmals nicht gelungen war, in Wurzen einzudringen, trieben sie am 5. November 1558 den Wurzenern das Vieh (darunter sollen allein 700 Schweine gewesen sein) von der Weide vor dem Eilenburger Tor hinweg. ${ }^{28}$ Nacheilende Wurzener holten sich nur noch blutige Köpfe, fünf von ihnen blieben tot auf dem Felde liegen.

1581 schließlich gab Johann IX. von Haugwitz als letzter Bischof von Meißen dem kurfürstlichen Druck nach: Auf dem Wurzener Schloss „resignierte“ und „kapitulierte“ er am 20. Oktober vor den Vertretern des protestantischen sächsischen Kurfürsten, er trat zurück. ${ }^{29}$ Er wechselte sein Bekenntnis und heiratete seine Nichte (sein durch ihn selbst getauftes Patenkind) und zog sich auf seinen Alterssitz Schloss Ruhetal in Mügeln zurück. Doch das Bischofsland wurde nicht so ohne Weiteres Kursachsen einverleibt. Wenn auch immer mehr nur formaler Art, führte es doch aus reichsrechtlichen Gründen bis 1818 noch ein politisches Eigenleben, verwalteten „die des Stifts Meißen verordneten Hauptmann, Kanzler und Räte" die Stiftsstadt und das Stiftsland im Auftrag der kurfürstlichen Regierung. Es war damit ein Beispiel geworden für die Zählebigkeit überkommener feudaler Strukturen und für den territorialen Flickenteppich im Heiligen Römischen Reich Deutscher Nation.

\section{Schwarzer Tod, Roter Hahn und Brandschatzungen. Das Jahrhundert der Schrecken und des Niedergangs}

Für damalige Begriffe war Wurzen um 1600 eine wohlhabende Stadt, gleichzeitig mit etwa 5.000 Einwohnern (das wichtige Leipzig hatte damals „nur“ viermal mehr) und knapp 500 bebauten Grundstücken nach Grimma die zweitgrößte des mittleren Muldegebietes. ${ }^{30}$ Allerdings lagen nur etwa 130 „Herdstellen“ innerhalb der Mauer. Die meisten Einwohner wohnten eigentlich vor den Toren, in den „Vorstädten“, von denen die „Neue Stadt“ oder das Wenzelsviertel vor dem Wenzelstor südlich des Rietzschketales die größte war. Die Stadtkirche St. Wenceslai lag - und das ist sehr merkwürdig - außerhalb der eigentlichen Rechtsstadt, in der es sehr eng zuging. Den vor der Mauer wohnenden "Pfahlbürgern" war bereits 1413 nach Bau eines Grabens um die südliche Vorstadt durch Bischof Rudolf von der Planitz 


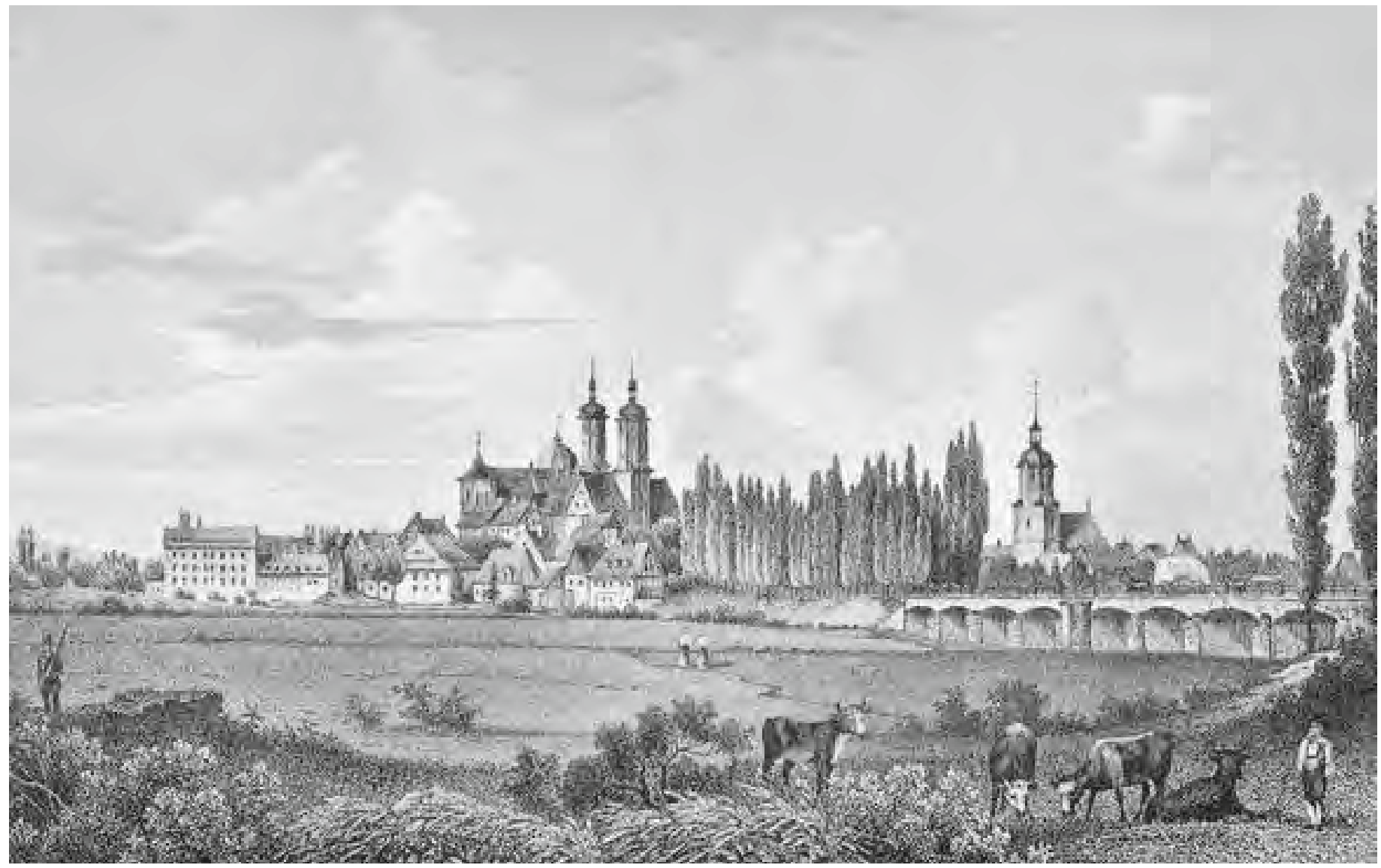

(1411-1427) das Bürgerrecht zugestanden worden. ${ }^{31} 1512$ stellte dann Bischof Johann VI. von Salhausen sein Vorhaben, die südliche Vorstadt auch zu ummauern, wegen der $\mathrm{zu}$ erwartenden hohen Kosten ein. ${ }^{32}$

Die Bürger der Stadt waren in dieser Zeit vor allem Handwerker: Schuhmacher, Böttcher, Schmiede, Fleischer, Bäcker, Tuchmacher, Bleicher, Färber, Schneider, Kürschner, Wagner, Kannegießer, Töpfer und andere. Die Zeit des wirtschaftlichen Aufstiegs im 16. Jahrhundert hatte aber auch die Bevölkerung sozial stark differenziert. Bürger war nicht gleich Einwohner oder Schuster nicht gleich Schuhmacher. Es gab zahlreiche Mägde, Tagelöhner, Gesellen - Menschen in Dienstabhängigkeit und auch das, was man später „Stadtarmut“ nennt. Diese Bevölkerungsteile stellten - nach den spärlichen Quellen, die wir noch haben - die Mehrheit der Einwohner. Dagegen gab es eine kleine Schicht von nur wenigen Familien, die so etwas wie ein Patriziat darstellte: Geistliche, Juristen, Kaufleute, Stadtgutbesitzer oder einzelne Handwerker, deren Namen immer wieder in den Akten erscheinen. Aus diesen Kreisen kamen die Mitglieder des Rates, der noch 1642 ausdrücklich betonte, dass er „keiner fremden Person bedürftig“ sei (und das nach den Bevölkerungsverlusten im Dreißigjährigen
Krieg). Diese Ratsfamilien vor allem profitierten aus der zunächst allgemein günstigen Finanzlage der Stadt, die sich aus der Betriebsamkeit ihrer Bürger und aus den zahlreichen Einnahmen wie Gerichts-, Markt-, Geleits-, Fähr-, Viehgeldern oder Pachtgebühren ergab. Der Rat selbst war auch mehrfach Grundbesitzer geworden und besaß mit Müglenz zeitweise sogar ein ganzes Dorf. Wichtigstes Exportgut der Stadt war ihr vorzügliches Bier. Vom Wohlstand der Stadt zeugten beachtliche öffentliche Bauten wie das Zeug- bzw. Gewandhaus oder die Lateinschule, die aus der Vereinigung von städtischer Schule und der alten Stiftsschule während der Reformation auf der Domfreiheit entstanden war; den Anfang eines städtischen Gesundheitswesens markierten das Jacobs- und das Johannishospital.

Mit dem aufziehenden 17. Jahrhundert fand diese bescheidene Blüte ein abruptes Ende durch Pest, Feuer und Krieg. Mit zwei Pestjahren hatte sich in Wurzen das Jahrhundert der Reformation verabschiedet. Nach dem verheerenden Stadtbrand am Gründonnerstag 1602 versetzte die Pest 1607 der Stadt einen ersten tödlichen Stoß. 1.450 Einwohner, etwa ein Drittel, fielen der Epidemie zwischen Mai und November zum Opfer. ${ }^{33}$ An sie erinnert seit 1687 das so genannte „Pesthäuschen“ auf dem
Ansicht Wurzens vom Bennewitzer Muldenufer. Stich, um 1850

26 Schöttgen 1717, S. 568.

27 Schöttgen 1717, S. 568-577.

28 August Schumann, Vollständiges Staats-, Post- und Zeitungslexikon von Sachsen. Dreizehnter Band, Zwickau 1826, S. 371.

29 CDS II,3, Nr. 1487-1492.

30 Rudolf Schmidt, Der Grenzverlauf zwischen den Ämtern Grimma und Wurzen im 16. 17. und 18. Jahrhundert und seine Bedeutung für die kursächsische Amtsverfassung .In: Mitteilungen des Wurzener Geschichtsvereins Bd. 2, Heft 1 (1914), S. 72

31 Schöttgen 1717, S. 19-20.

32 Schöttgen 1717, S. 21.

33 Schöttgen 1717, S. 663-675. Ausführliche Darstellung nach Rektor Johann Lasmann, der die Epidemie über lebte: Der trawrige Sommer. Im grossen sterben zu Wurtzen. Anno 1607. Mit Reimen beschrieben, Leipzig 1608 . 


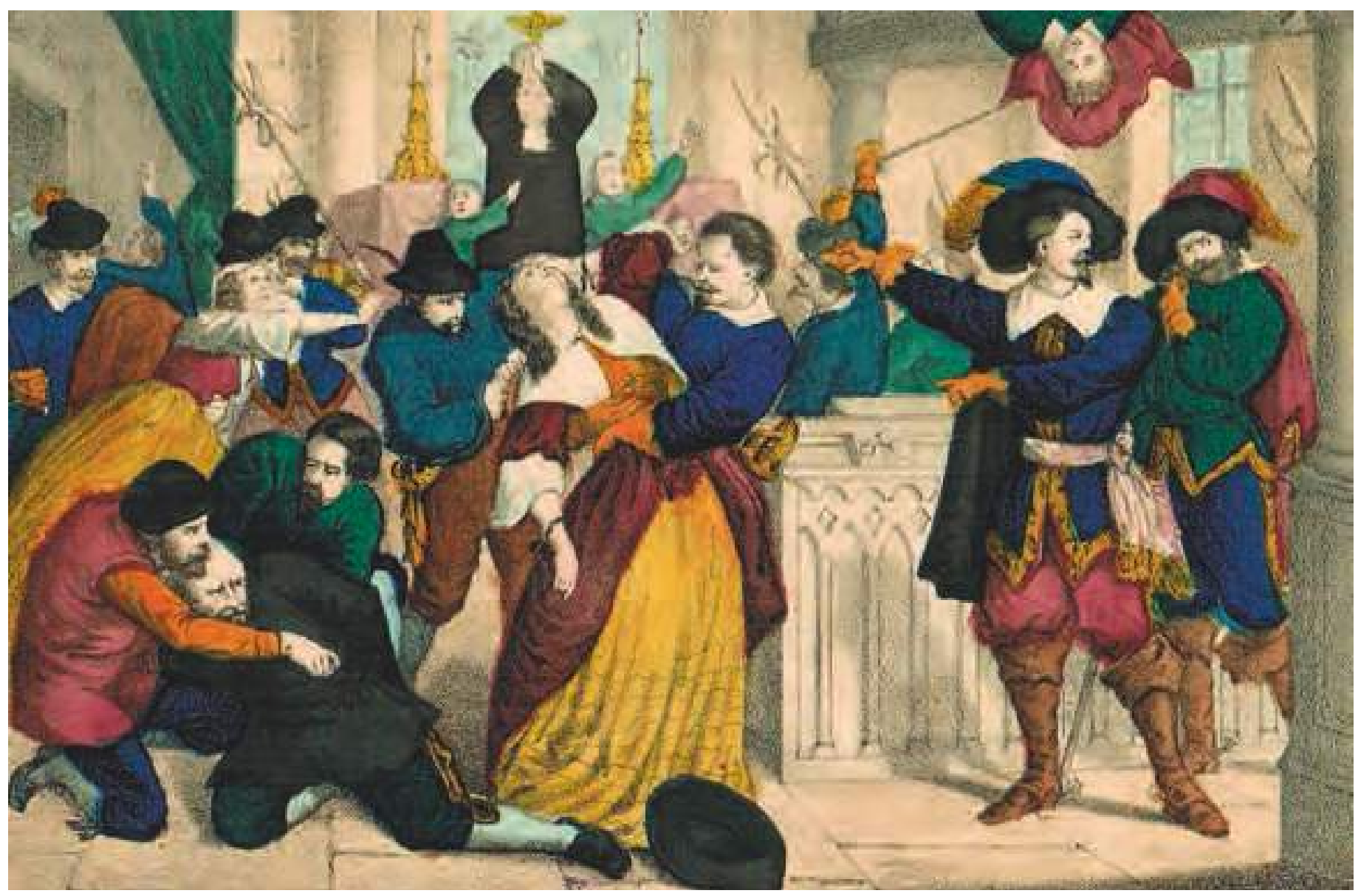

Die Wurzener Kreuz- und Marterwoche 1637. Kolorierte Lithographie, um 1860

34 Ihrer wurde 1937 besonders gedacht: Walther Putzger, Wurt znische Creutz- und MarterWoche 4.- 7. April 1637. In: Mitteilungen des Wurzener Geschichts- und Altertumsvereins Bd. 4, Heft 1 (1937).

35 Walter Koch, Vom ehemaligen "Neuen Hause“. In: Wurzener Erzähler 36 (1934), S. 1 f.; der, Als die Stadtmauer in Wurzen abgebrochen wurde (II). In: Der Rundblick 3/1957, S. 103/104.

36 Walter Troitzsch, Die Wurzener Ratswahlen (1637-1832). In: Mitteilungen des Wurzener Geschichts- und Altertumsvereins Bd. 1, Heft 1 (1910), S. 65 f.

37 Ein kurfürstliches Mandat von 30.12.1712 legte fest, dass der Warenverkehr, der bislang über die Eilenburger oder Grimmaer Brücke gehen musste, auch die Wurzener Muldenpassage be nutzen dürfe. Damit waren alle z.T. seit dem 15. Jh. bestehenden Beschränkungen für die Wurzener Mulde-Querung aufgehoben. Das Fehlen einer Brücke fiel nun besonders ins Gewicht. früheren Alten Friedhof. Die Pest suchte die Stadt auch 1610 und 1625 heim. Doch das war nur der Anfang.

Der Stadtbrand am 5. April 1631 fiel schon in die Zeit des Dreißigjährigen Krieges. Noch im gleichen Jahr durchzogen kaiserliche Truppen plündernd Nordwestsachsen; drei Jahre später legten kursächsische Truppen der Bevölkerung hohe Kontributionen auf. Das alles ist aber noch nichts gegen das, was sich 1637 in der „Wurtznischen Creutz- und Marter-Woche“ abspielen sollte. ${ }^{34}$

Nachdem schwedische Abteilungen der Stadt seit Jahresbeginn 1637 hohe Loskaufsummen abgepresst hatten, wurde diese vom 4 . April an durch schwedische Soldaten erbarmungslos terrorisiert und geplündert, schließlich am Karfreitag in Brand gesteckt. Wurzen brannte bis auf wenige Gebäude vollständig nieder. Nur ein Zehntel der Einwohner blieb lebend auf der Brandstatt zurück. Aber auch jetzt noch wurden die Überlebenden drangsaliert und beraubt. So 1641, $1643 / 44 / 45$, ja noch 1648 . Als in diesem Jahr der Krieg an Entkräftung zu Ende ging, erinnerte nichts mehr an die einst wohlhabende und blühende Stadt. Die Pest wütete noch mehrmals zwischen den Ruinen (letztmalig 1680), und wiederholte Stadtbrände unterbrachen immer wieder den nur schwerfällig in Gang kommenden Wiederaufbau, der sich so bis ins nächste Jahrhundert hinschleppte.

Erst nach reichlich 200 Jahren sollte Wurzen wieder 5.000 Einwohner zählen. Seine wirtschaftliche Kraft und das Selbstbewusstsein seiner Bewohner waren für lange Zeit bis auf den Grund zerstört.

\section{„Bey Wurtzen ist's fatal...“. \\ Die kursächsische Stiftsstadt im 18. Jahrhundert.}

Wenn man die Ausmaße der Katastrophe ins Auge fasst, welche der Dreißigjährige Krieg über Wurzen hereinbrechen ließ, so ringt es doch Anerkennung ab, wie viel Lebenswillen seine Bewohner in den nachfolgenden Jahrzehnten beim Aufbau der Stadt und bei der Erneuerung ihrer wirtschaftlichen Grundlagen beweisen sollten. Aber die Zeiten der Prosperität waren vorbei. Sehr langsam wurde gebaut, außerdem - die Not der Zeit begünstigte das - wohl recht nachlässig; und nur wenige konnten es sich leisten, wieder großzügig zu sein. Hundert Jahre lang ließen große Brände immer wieder Ruinen und Schuttplätze entstehen. 
Aus dem Krieg waren die großen Territorialherren als die eigentlichen Sieger hervorgegangen. Auch die sächsischen Kurfürsten begannen, in ihren Herrschaftsgebieten absolutistisch zu regieren. Wurzen und das Wurzener Land wurden 1663 durch die „Postulatio perpetua" noch stärker in den albertinischen Staatsverband integriert und wie ein kursächsisches Amt verwaltet. Das bedeutete für die Wurzener zunächst eine immer stärker angezogene Steuerschraube, aber auch häufige Reglementierung von Rat und Bürgerschaft durch die „kurfürstliche Stiftsregierung" auf dem Schloss. Der Rat war kein selbstbewusst auftretendes Organ der Bürger mehr, er wandte sich jetzt untertänig an den Kurfürsten und verwandelte sich zunehmend selbst in ein devotes Vollzugs- und Reglementierungsinstrument. Gleichzeitig benutzten die Ratsmitglieder ihre Ämter immer offensichtlicher, um tüchtig in die eigene Tasche zu wirtschaften. Sie schoben sich die Ämter und Einnahmen wechselseitig $\mathrm{zu}$, wachten eifersüchtig über ihre Privilegien und beutelten mit Aufgeldern und Zinsen, notfalls auch mit List oder Gewalt, Einwohner und Fremde.

1700 musste die Stiftsregierung den Rat mahnen, die Bürger nicht zusätzlich mit Abgaben zu belasten, damit diese die Steuern und Kontributionen (inzwischen war der Nordische Krieg ausgebrochen) aufbringen können. Die Korruption gedieh bei den Herren der Stadt, die es ihrem Pracht liebenden und prunksüchtigen Landesherrn, dem starken August, im Kleinen nachtun wollten.

Nachdem 1704 ein großer Stadtbrand wieder einmal Teile der Stadt an Schloss, Schuhgasse und Johannisgasse niederlegt hatte, waren die Ratsherren als erste dabei, mit den Grundstücken zu spekulieren. Sogar die alte Stadtmauer wurde zu Geld gemacht: Zwischen Schloss und Eilenburger Tor wurde sie abgerissen, um Baumaterial unter anderem für das „Neue Haus“ des Rats am Ausgang der Johannisgasse zu gewinnen, aus dessen Vermietung die ständig leeren Kassen aufgefüllt werden sollten. ${ }^{35}$ Auch ist wohl manche erhobene Münze nicht erst ins Stadtsäckel gefallen. Mehrfach, so 1734 oder 1757, wurden Ratsmitglieder wegen „Defecta“ in den Stadtrechnungen von der Stiftsregierung suspendiert. ${ }^{36}$

Die Leidtragenden, die einfachen Bürger, die nach Gewohnheit und Recht ihrer Arbeit nachgingen, scheinen das nicht immer hingenommen zu haben. Schon 1703 wurden sie ernstlich ermahnt, „sich verbotenener heimlicher Versammlung zu enthalten“. Das war schon während des Nordischen Krieges, in dem Wurzen
1706/07 abermals von den Schweden besetzt wurde und Kriegslasten tragen musste. Auch die Preußen, die im Siebenjährigen Krieg Sachsen besetzten, hielten sich an den Wurzenern schadlos: Das preußische Feldkriegsdirektorium in Torgau presste, teilweise unter Androhung „militärischer Execution“, der Stadt neben Naturalleistungen fast 60.000 Taler ab.

Der Aktionsraum der Bürger wurde so immer wieder beschränkt, die übergroßen steuerlichen Belastungen erstickten den Tatendrang, die Wurzener „muckten“ bis ans Ende des 18. Jahrhunderts kaum mehr auf. So blieb auch die wirtschaftliche Basis der Stadt bis 1800 vergleichsweise bescheiden. Zunftzwänge und -streitigkeiten engten Entwicklungsmöglichkeiten immer augenscheinlicher ein. Obwohl unter August dem Starken Wurzen auf dem Crostigall eine Poststation erhielt und später auch Etappenort einer Kurierpost wurde, bekam die Stadt keine Brücke über die Mulde. Fähr- und Geleitsgeld waren nun mal nicht wegzudenkende Einnahmen für Rat und Fiskus. ${ }^{37}$ Die städtische Entwicklung begann endgültig zu stagnieren. Wurzen vergrößerte sich kaum. Kriegerische Wirren rissen es zuweilen in ihren verderblichen Strudel, aber der Fortschritt schien - wie der Handelsverkehr einen Bogen um die Stadt zu machen. Das Leben schlich ausgedünnt und entschleunigt dahin.
38 An den Stadttoren wurde die Akzise, eine Verbrauchssteuer, auf verschiedene Waren erhoben.

39 Der obersten Landesbehörde direkt unterstellt.

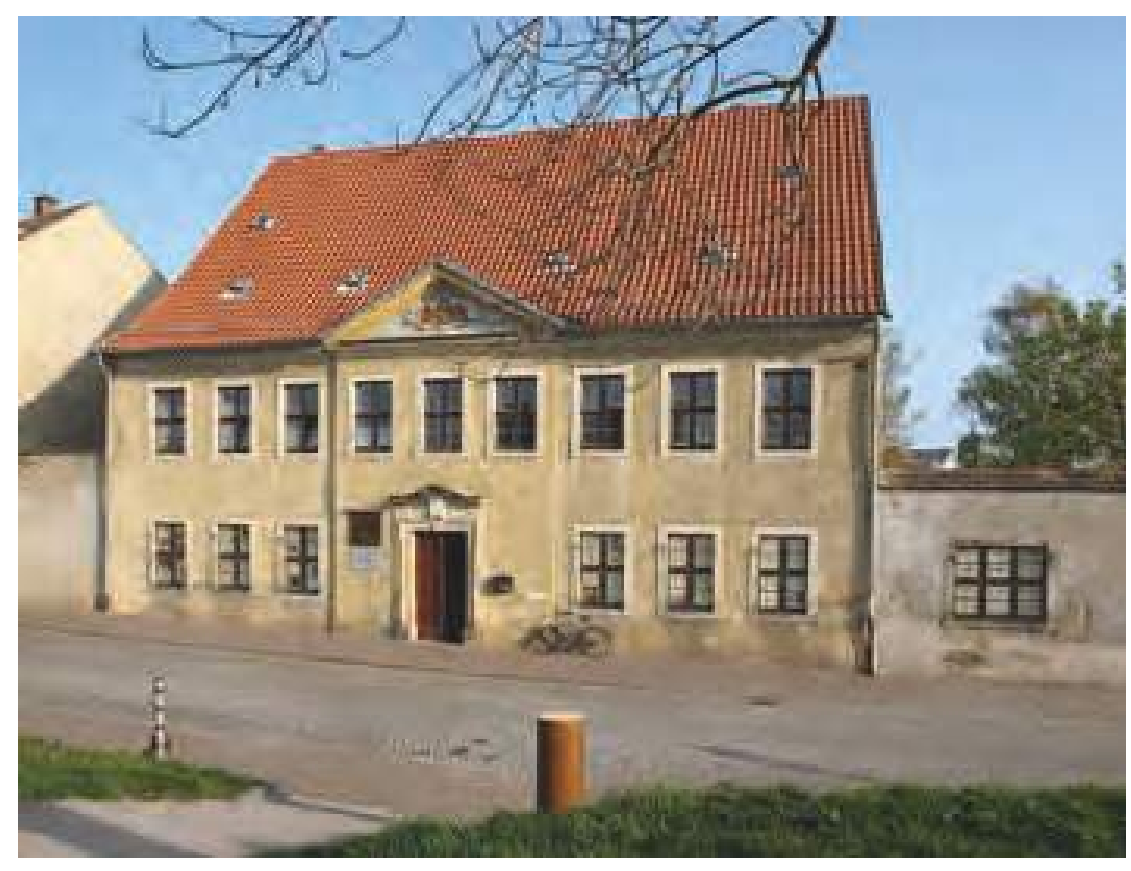

Für das Ende des 18. Jahrhundert notierte man unter Wurzen, dass die „accisbare“38 Stadt „schriftsässig“39 sei und eine Fähre habe. „Sie hat in der Ringmauer weder Kirchen, Schulen
Das barocke Freihaus Crostigall 14 , später Geburtshaus von Joachim Ringelnatz Foto: Wolfgang Ebert 
40 „Gangbare Schock“, für die Schocksteuer veranschlagter Grundstückswert, Grundsteuer.

41 „Hufe“. Die sächsische Hufe entsprach im 18./19. Jh. $36 \mathrm{Ak}$ ker, d. h. 19,9223 Hektar. Wurzen umfasste also um 1779 etwa $10,06 \mathrm{~km}^{2}$ (Zum Vergleich 2013: $\left.68,79 \mathrm{~km}^{2}\right)$.

42 Friedrich Gottlob Leonhardi (Hrsg.), Erdbeschreibung der Churfürstlich- und HerzoglichSächsischen Lande. Zweyter Band. Leipzig 1803, S. 917 f.

$43 \mathrm{Vgl}$. August Schumann, Vollständiges Staats-, Post- und Zeitungslexikon von Sachsen. Bd. 13. Zwickau 1826, S. 369327. Die damalige bauliche Situation der Stadt verdeutlicht das "Stadtmodell Wurzen 1820 “ (2006) im Kulturgeschichtlichen Museum der Stadt.

44 Neben der Gerichtsbarkeit der Stadt und des Amtes bestand die Eigengerichtsbarkeit des Domkapitels, der Stadtmühle, des Steinhofs und teilweise der Gaudlitzhäuser. Auch die rechtliche Stellung der "Bleiche“ war nicht eindeutig festgelegt.

45 August Schumann, a.a.O., S. 384. Einer typischen „Ackerbürgerstadt" entsprach Wurzen nicht ganz, denn der Anteil der Bürger, die in der Landwirtschaft arbeiteten und von ihr lebten, war zu gering. Die verschiedenen und auch auf Export orientierten Gewerbe und der Handel bildeten das wirtschaftliche Rückgrat der Stadt, die zugleich eine von der Landesherrschaft autorisierte Zentralität auszeichnete (Sitz von Unterbehörden, Garnison). Das erklärt auch den für eine damalige Klein stadt recht hohen Anteil von "graduierten und beamteten Personen" (August Schumann, a.a.O.). Anders bewertet Walter Schlesinger, a.a.O., S. 367.

46 Die Industrialisierung der Stadt stellt umfassend dar Richard Klinkhardt, Die Wurzener Industrie 1797-2002, Beucha 2005. Zur damit verbundenen baulichen Entwicklung der Stadt vgl. Wolfgang Ebert, Stadthaus, Landhaus, Villa - Wohnsitze und Wohnformen des Wurzener Bürgertums 1840-1940, In: Erhalten. Erleben. Erinnern. Wurzener Unternehmer und ihre Villen. Herausgegeben von der Stadt Wurzen, Wurzen 2013, S. 19-33. etc. und nur 110 Häuser, in den Vorstädten aber mit Einschluß des Schlosses, der Kollegiat- und Stadtkirchen, Schule u.s.w. 270 Häuser mit 104091/2 gangb. Sch. ${ }^{40}, 501 \frac{1}{2}$ Huf $^{41}$ [...], 1921 Einwohner, welche von der Bierbrauerey, Strumpfstickerey, Leinweberey, Leinwandbleichen und den 3 Jahr- nebst 2 Viehmärkten, gute Nahrung haben. [...] 1779. lebten hier in 583 Fami-lien 1556 Einw. über 10 Jahr mit 153 Kühen und 209 Schaafen. Außer der [...] Stiftsregierung, Konsistorium und Superintendentur, befinden sich auch eine lateinische Schule und Poststation hier." 42

Im März 1768 - elf Jahr zuvor und zwei Jahrzehnte vor der französischen Revolution - reiste Johann Wolfgang Goethe von Leipzig über Wurzen nach Dresden und könnte an der Mulde die Anregung bekommen haben zu seinen Worten im „Urfaust“: „Bey Wurtzen ist's fatal, da muß man so lang auf die Fähre manchmal warten.“

\section{Später Abschied vom Mittelalter. Wurzen in der ersten Hälfte des \\ 19. Jahrhunderts}

Noch am 16. Oktober 1806, als nach der Schlacht bei Jena und Auerstedt französische Soldaten durch die Wurzener Stadttore galoppierten und sich in den Gassen und Häusern übermütig aufführten, mochten viele Wurzener die Ereignisse verständnislos und kopfschüttelnd zur Kenntnis genommen haben. Diesmal hatten die Völker nicht in der „hintersten Türkei“" aufeinander geschlagen, sondern das nachrevolutionäre Frankreich hatte unter seinem korsischen Kaiser dem erstarrenden feudalen Europa eine nachhaltige Lektion erteilt.

Mit Kanonendonner wurde Wurzen aus seinem Dornröschenschlaf geweckt, endgültig, wenn auch nicht gleich jeder begriff, dass nun manch alter Zopf fallen musste. Zunächst jedoch versuchte Bürgermeister Christian David Zopf, sich den Forderungen der Okkupanten $\mathrm{zu}$ widersetzen. Die ließen nicht mit sich spaßen und nahmen ihn kurzerhand nach Torgau in Haft. Inzwischen hatte sich ja auch sein Landesvater mit „Napoleum“ eingelassen. Bis 1813/14 trug die Stadt wieder Kriegslasten, wurde sie bis aufs äußerste ausgepresst, glich sie - ganz besonders 1812/13 - einem riesigen Heerlager. Ganze Armeen durchzogen Wurzen, an ihrer Spitze Männer wie Davoust, Ney, Marmont, Wintzingerode; und schließlich nahm Napoleon selbst vom 8. zum 9. Oktober 1813 Quartier in Wurzen. Als am 16. Oktober 1813 bei Leipzig tobte schon die Völkerschlacht -
Kosaken der napoleonischen Fremdherrschaft in Wurzen ein Ende machten, war diese wieder eine ausgeplünderte und für Jahrzehnte verarmte Stadt: ein vernachlässigtes Landstädtchen mit reichlich 2.000 Einwohnern. ${ }^{43}$ In ihm schien die Zeit stehen geblieben zu sein.

Doch die biedermeierliche Atmosphäre in den Gärtchen, Gässchen und Stuben trog. Vieles war doch anders geworden. Langsam zunächst, aber unaufhaltsam trennte sich die Stadt in den Folgejahren von ihrer mittelalterlichen Physiognomie und Lebensweise. 1818 wurde das Stiftsamt aufgehoben, ab 1828 verschwanden die Stadttore. Trotz aller Restaurationsversuche begannen auch in Wurzen liberale Ideen zu keimen, kam es bereits zu Ansätzen einer Industrialisierung. Zwei wichtige Ereignisse fielen für Wurzen symbolhaft zusammen: 1830/31 wurden die für den anwachsenden Warenverkehr wichtigen Straßenbrücken über die Mulde, Aue und Mühlgraben gebaut; die Eilenburger Brücke gehörte ja jetzt zu Preußen. Gleichzeitig griffen revolutionäre Stimmungen aus Leipzig nach Wurzen über: Die Bürgerschaft forderte am 30. Oktober 1830 in einem Schreiben die totale Umwandlung der Landesverfassung und die Wahl der Stadtverwaltung durch Stadtverordnete. Im März erfolgte dann erstmalig die Wahl sogenannter „Kommunerepräsentanten“. Die in Sachsen 1832 verabschiedete neue Städteordnung führte auch in Wurzen die Auflösung Jahrhunderte alter Strukturen herbei. Die Eigengerichtsbarkeit einzelner Stadtteile bzw. Eigentümer oder der Stadt selbst erlosch ${ }^{44}$, Privilegien wurden abgeschafft. Von 1839 bis 1843 bildete sich die neue Stadtgemeinde Wurzen.

Nachdem die erste deutsche Ferneisenbahn 1839 die Stadt mit Leipzig und Dresden verbunden hatte, begann deren alles prägende Industrialisierung: 1840 wurde die Tapetenfabrik August Schütz gegründet. Ab 1847 baute Friedrich Krietsch die alte Stadtmühle zum ersten Großbetrieb aus. Im gleichen Jahr wurde die "Spar- und Leihkasse" eröffnet. Wurzen veränderte sein Aussehen und begann langsam zu wachsen. Gegenüber dem Beginn des Jahrhunderts hatte sich die Einwohnerzahl um 1850 mehr als verdoppelt. Auch die sozialen Unterschiede nahmen zu. Die Zahl der Lohnarbeiter wuchs rasch an, zugleich radikalisierte die industrielle Entwicklung das zahlenmäßig starke Kleinbürgertum. Andererseits formierte sich als Gegenreaktion ein konservativer Konsens zwischen den unterschiedlichen restaurativen Schichten. Als 1848 in Sachsen eine revolutionäre Situation heranreifte, hatten sich auch in Wurzen die Kräfte polarisiert. 


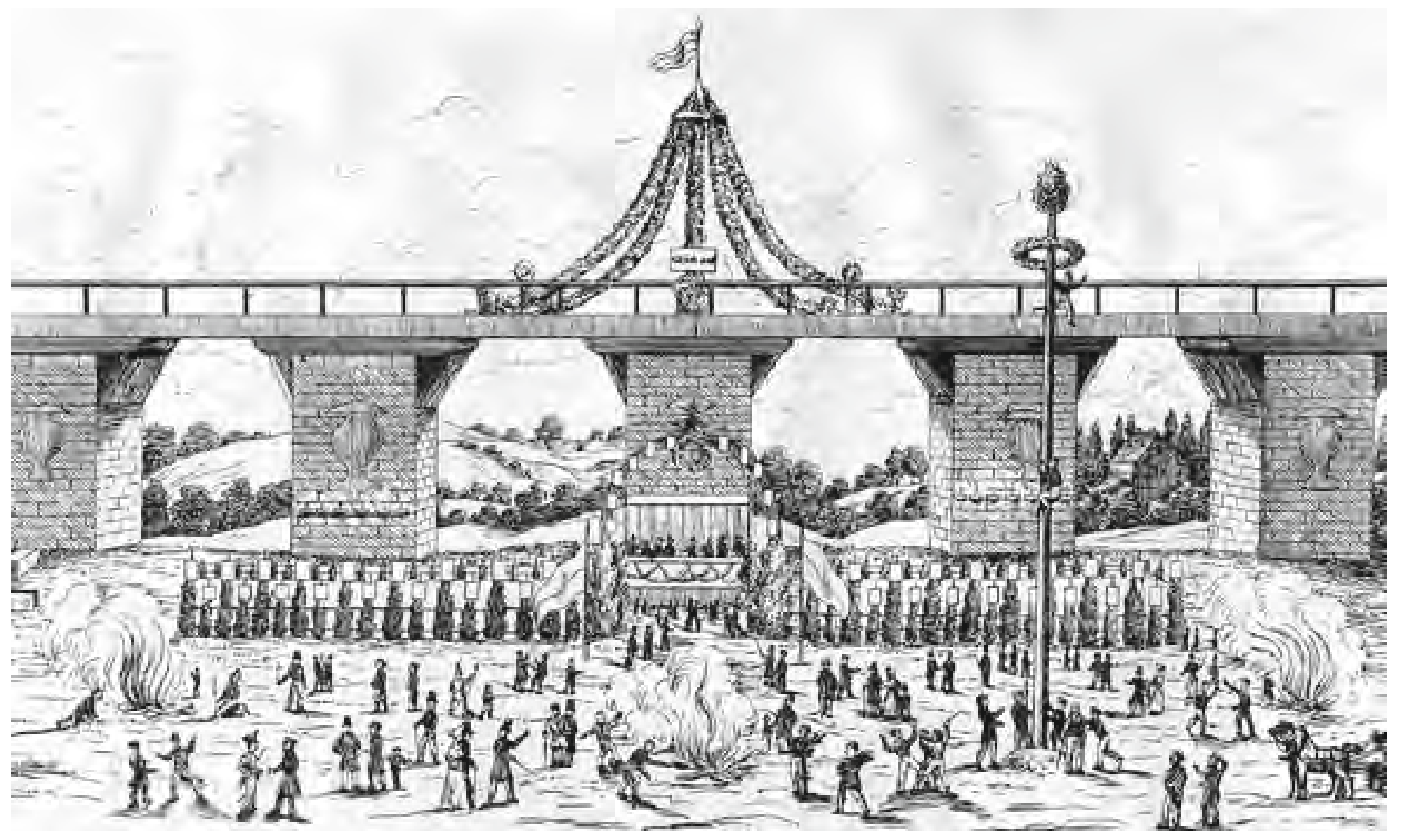

\section{Von der Ackerbürgerstadt ${ }^{45}$ zum Industriestandort}

Im Frühjahr 1848 kam es erstmalig in Wurzen zur Bildung zweier politischer Vereine: Die „Demokraten“, vor allem kleinbürgerliche Kreise um den seit 1845 amtierenden Bürgermeister Julius Theodor Schmidt (1811-1861) an der Spitze, traten für eine demokratische Umgestaltung ganz Deutschlands und für die endgültige Abschaffung noch bestehender feudaler Bindungen und Lasten ein. Ihnen gegenüber standen die „Konservativen“, in der Hauptsache Offiziere, Beamte und Grundbesitzer. Die Ereignisse in Preußen und Österreich fanden bei den Wurzenern begeisterten Zuspruch. Schmidt wurde in die Frankfurter Nationalversammlung gewählt. Er unterstützte aktiv die Erhebung 1849 in Dresden. Doch auch in Sachsen kam die bürgerliche Revolution nicht zum Sieg. Bürgermeister Schmidt entzog sich 1850 einem drohenden Hochverratsprozess durch seine abenteuerliche Flucht nach Amerika.

Das Bürgertum hatte die gesellschaftlichen Verhältnisse nicht grundsätzlich nach seinen Vorstellungen verändern können, aber die kapitalistische Entwicklung wurde bereits durch Teilergebnisse auch in Wurzen ungemein beschleunigt. Steinkohlengas wurde in der Stadt ab 1859 erzeugt und verwendet. Zahlreiche größere und mittlere Industrieunternehmen wurden gegründet, so 1856 die Velourstaubfabrik (aus der 1873 die Teppichfabrik hervorging), 1861 die Filzfabrik, 1862 die „Bronze“ (Fertigung von Beleuchtungskörpern), 1866 das Drahtseilwerk. Die größtenteils von außerhalb nach Wurzen kommenden Unternehmer nutzten Wurzens günstige Standortfaktoren wie Wasser (Mulde und Mühlgraben), seine billigen Arbeitskräfte und niedrigen Bodenpreise sowie den „Fühlungsvorteil“, den die Nähe der Messestadt Leipzig mit sich brachte. ${ }^{46}$ Nur wenigen einheimischen Handwerksbetrieben gelang es, sich zu Industriebetrieben zu entwickeln.

Ein Großteil der Handwerker wurde zunehmend proletarisiert. Diese und die in die Stadt strömenden Arbeitskräfte vom Lande ließen eine neue soziale Schicht entstehen, die zahlenmäßig rasch anwuchs und sich in erste organisatorische Formen fand, ehe sich das neue Wurzener Besitzbürgertum als gesellschaftliche Klasse politisch konstituieren konnte. 1865 gründeten die Zigarrenmacher ihre „Kranken- und Unterstützungskasse“. Sie steht für den Beginn aller Aktivitäten, die später zu Gewerkschaften, Fachverbänden und zu den Arbeiterparteien führten.
Einweihung der Eisenbahnbrücke der Leipzig-Dresdner Eisenbahn bei Wurzen, 1838 


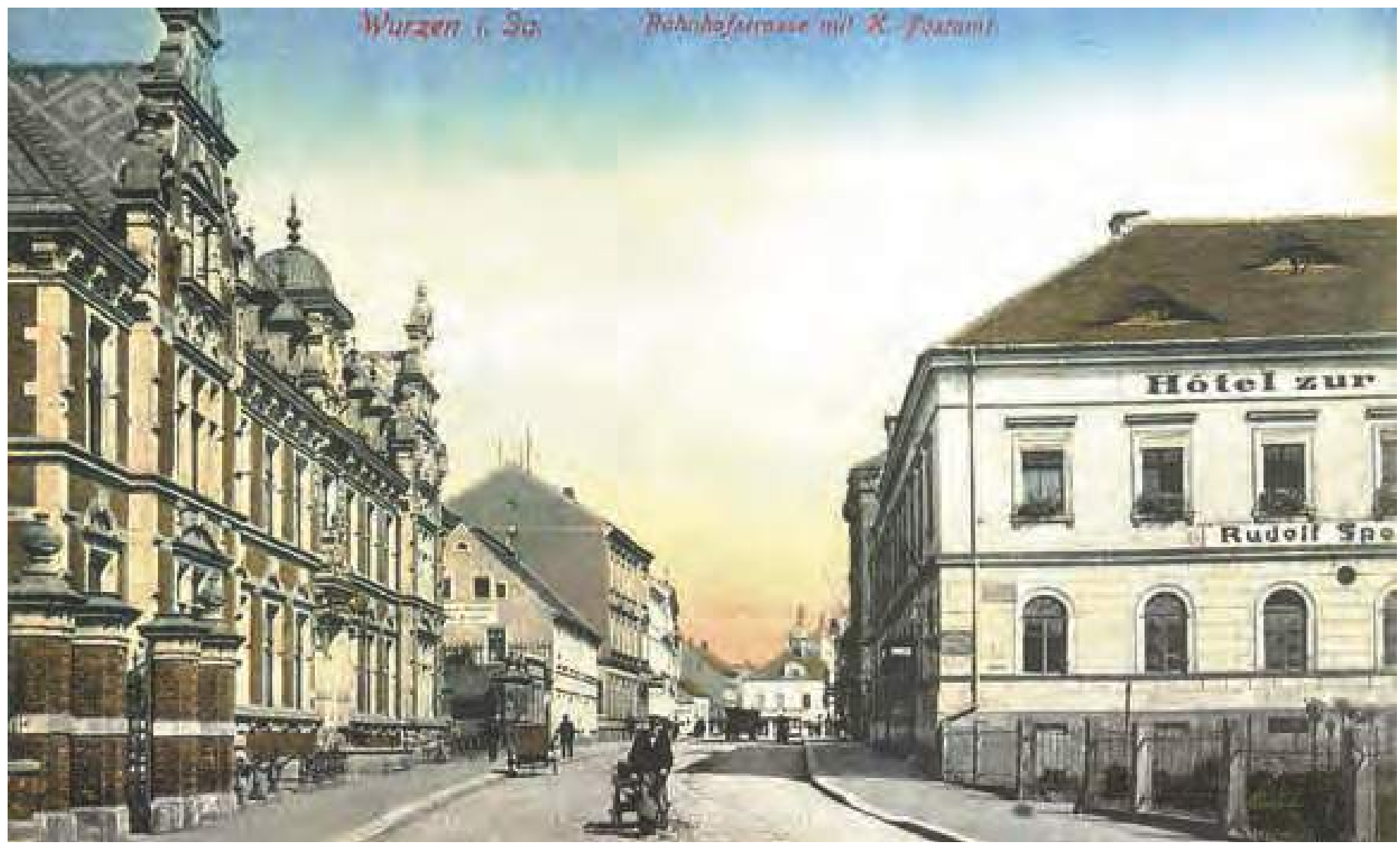

Blick in die Bahnhofsstraße mit dem Postamt. Postkarte, um 1900

47 Geschichte der Sozialdemokratie im Raume Wurzen-GrimmaOschatz. Herausgegeben von der Friedrich-Ebert-Stiftung, Büro Leipzig, Leipzig 1993, S. 23-27.

48 Richard Klinkhardt, Die Geschichte der Wurzener Kasernen. In: Der Rundblick 2/1992, S. 28-30; 3/1992, S. 38/39; 4/1992, S. 48/49.

49 Karl Mucker gehörte seit 1894 der SPD an und war 1903 an der Gründung des Sozialdemokratischen Volksvereins in Wurzen beteiligt, seit 1910 auch Stadtverordneter, 1919-1824, 1927-1929, Anfang 1933 und 1947-1950 Stadtverordnetenvorsteher. 1946 Mitglied der SED. 1920-1922 Landtagsabgeordneter.
Obwohl Wurzen erst nach 1850 wieder die Einwohnerzahl erreichte, die es am Ende des 16. Jahrhunderts gehabt haben soll, zeigte es um 1870 bereits die typischen Merkmale einer Industriestadt. Zahlreiche Schornsteine überragten die Dächer der Stadt und zeugten davon, dass Dampfmaschinen in ihr Einzug gehalten hatten.

Nach dem Deutsch-Französischen Krieg und der Reichsgründung geriet auch Wurzen in den Taumel der Gründerjahre. Über ein Dutzend neuer Industriebetriebe siedelten sich an, vorwiegend Maschinenbaufabriken entlang der Eisenbahnlinie. Die Stadt platzte aus ihren Nähten und veränderte durch Abrisse und Neubauten auch im Innern mehr und mehr ihr ursprüngliches Aussehen. Neue Straßen und Plätze entstanden, neue Wohnviertel und Schulen, im Norden der Stadt ein großer Park; ab 1893 versorgte ein städtisches Wasserwerk und eine Druckwasserleitung die Haushalte und Fabriken mit Trinkwasser.

Die Sozialdemokratie - zunächst behindert durch kleinbürgerliche Umwelt und fortlaufende Restriktion durch Rat und Staat - begann sich zu regen. Gerade während des Bismarck'schen Sozialistengesetzes gewann sie durch Kontakte mit Wilhelm Hasenclever, Julius Künzel, August Bebel oder Wilhelm Liebknecht an Profil und Organisationsgrad. Ab 1884 entstanden zahlrei- che Gewerkschaften und Fachverbände. Fünf Jahre später - mitten in der Baukonjunktur kam es zum ersten großen Ausstand der Bauarbeiter. Seit 1892 waren die Wurzener Sozialdemokraten in der Stadtverordnetenversammlung vertreten, 1903 gründeten sie einen selbstständigen Unterbezirk der SPD. ${ }^{47}$

Das Jahr 1911 bleibt für die Entwicklung Wurzens in mehrfacher Hinsicht bemerkenswert: „Vater Schöne“ beendete als letzter Türmer auf der Wenceslaikirche seinen Dienst, Feuermelder, Telefon und erstmalig eine Turmuhr ersetzten ihn; das neue Stadtkrankenhaus an der Eilenburger Straße wurde eingeweiht, der Bahnhof völlig umgebaut und erweitert; die Elektrizität war in die Stadt eingezogen. Innerhalb eines Jahrhunderts hatten sich die Einwohnerzahl verfünffacht, die Fläche der Stadt verdoppelt, deren Aussehen und Infrastruktur völlig verändert. Sie breitete sich vor allem nach Osten hin in engen und schmucklosen Wohnquartieren aus. Der Stadtrand war geprägt durch repräsentative Wohnsitze des in Wurzen neu entstandenen Besitz- und Bildungsbürgertums. 44 hohe Schornsteine, fünf Banken, sechs Schulen und zwei Kasernen versinnbildlichten wirtschaftliche und politische Macht. Elektrische Gütertransportbahn zwischen Krietschmühle und Bahnhof bzw. dem Braunkohlenschacht „König Albert“ oder das 


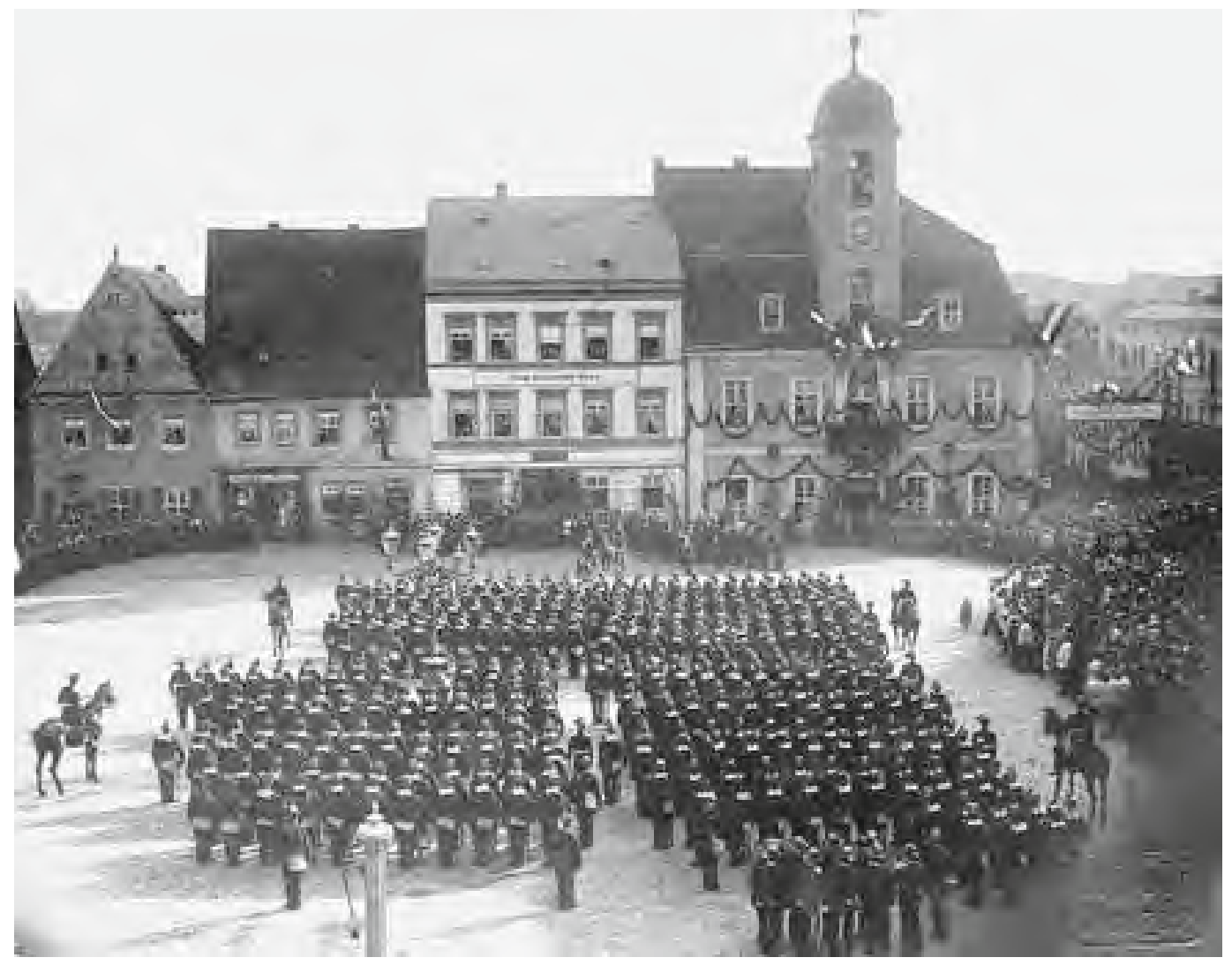

Motorboot „Martha“ auf Mühlgraben und Mulde vermittelten einen Hauch technischen Fortschritts, der soziale blieb noch ein heiß umkämpftes Ziel.

Am Ende des 19. Jahrhundert war Wurzen auch als Garnisonsstadt ausgebaut worden. Eine Infanterie- und eine Artilleriekaserne begrenzten jetzt die Stadt im Norden. ${ }^{48}$ Hier prägten die Soldaten wesentlich das Leben der Stadt. Auch nach Ausbruch des Ersten Weltkrieges blieb der Wurzener Norden eine aktive Zone: 1917 wurde hinter der Infanteriekaserne sogar ein Flugplatz angelegt, in der Kaserne eine Fliegeraufbauschule geschaffen. Von hier gingen auch am Ende des Krieges die Aktivitäten eines der ersten Soldatenräte in Sachsen aus.

\section{Von der Novemberrevolution zu Nationalsozialismus und Krieg}

Nach Ausbruch der Novemberrevolution löste der Wurzener Arbeiter- und Soldatenrat unter seinem Vorsitzenden Max Mucker (18761960) $)^{49}$ am 11. November 1918 die Stadtverordnetenversammlung auf und suspendierte bis zum 18. Dezember auch den Rat. Nach der Reichsrätekonferenz und den Wahlen zur Nationalversammlung konnten nach Neuwahl der Stadtverordneten am 9. Februar 1919 in Wur- zen zwar insgesamt 14 Sozialdemokraten (2 SPD, 12 USPD) ins Stadtparlament einziehen, aber das alte Stadtregiment blieb weitgehend erhalten.

Bürgermeister Friedrich Seetzen (1869-1943) ${ }^{50}$ und Stadtrat Walter Troitzsch, die wichtigsten Vertreter der bisher dominierenden Deutschnationalen, mussten sich mit den neuen Verhältnissen abfinden. ${ }^{51}$ Die Arbeiter- und Soldatenräte wurden aber sehr schnell wieder in die Bedeutungslosigkeit gedrängt. Eine ausgeprägte und polarisierte Parteienlandschaft entstand und prägte das politische Leben der Stadt während der Nachkriegskrise.

Die Idee einer proletarischen Revolution, wie sie sich im Oktober 1917 in Russland ereignet hatte, wurde von einer zunächst kleinen Gruppe von linken SPD-Mitgliedern wach gehalten, die am 28. Juli 1919 die Ortsgruppe der KPD begründeten. Unter ihnen befand sich der aus Bennewitz stammende Albert Kuntz (1896$1945)^{52}$, dessen Name bis 1924 mit den Aktivitäten der Wurzener Kommunisten verbunden bleibt. So vor allem 1920 während des KappPutsches oder während der spektakulären Aktion zur Beschlagnahme von Nahrungsmitteln im August 1923 bzw. in Auftritten gegen die Regierung Cuno. Immerhin konnten die Kommunisten 1921 bei den Stadtverordnetenwahlen zwei Sitze im Stadtparlament erringen
Appell der Wurzener Jäger am 1. April 1900 auf dem Marktplatz
50 Anton Friedrich Theodor Seetzen, Sohn eines aus Ostfriesland stammenden Kulturingenieurs, wurde in Großpösna geboren. Nach Besuch des Thomas-Gymnasiums studierte er in Leipzig Jura. Nach Wurzen kam er 1895 als besoldeter Stadtrat, wurde 1899 Bürgermeister, 1924-1927 Oberbürgermeister der Stadt. Er war 1905-1909 und 19141918 Mitglied des Landtages, 1901-1927 Mitglied der ev.-luth. Landessynode, 1927-1933 Präsident des ev.-luth. Landeskonsistoriums, 1924-1943 Domherr in Wurzen (Dechant, ab 1927 Probst).

51 Friedrich Seetzen, Aus meinem Leben, Typoscript (abgeschlossen Oktober 1939) im Archiv des Domkapitels Wurzen; ders. Wurzen im ersten Nachkriegsjahr. In: Mitteilungen des Wurzener Geschichts- und Altertumsvereins Bd. 3, Heft 2 (xxx); S. $138-142$.

52 Kupferschmied. 1924 Verurteilung wegen Landfriedensbruch. 1932/33 Mitglied des Preußischen Landtags. 1933 Inhaftierung (KZ Lichtenburg). Im KZ Mittelbau-Dora (Nordhausen) ermordet. 
Eisenbahn- und Industriegelände in Wurzen, 1924
53 Wolfgang Ebert, 1.4.1924 Austritt der Stadt Wurzen aus dem Bezirksverband Grimma. In: Der Rundblick, 15/1992, S. 194-195.

54 Boock entstammte einer Berliner Beamtenfamilie und wurde selbst Verwaltungsbeamter. 1927 Erster Bürgermeister in Wurzen, nach seiner Amtsenthebung 1933 Leiter eines Steuerbüros in Leipzig, Verbindung zum antifaschistischen Widerstand. 1944/45 Inhaftierung. 1945/46 erneut Bürgermeister in Wurzen. 1946-1961 Oberbürgermeister von Erfurt. Vorsitzender des Städte- und Gemeindetages der DDR.

55 Die NSDAP (Liste Dr. Brabant) erreichte in der letzten Stadtverordnetenwahl am 13.11.1932 ledigllich 29,5\% (gegenüber 1929 aber fast das Fünffache!). SPD und KPD behaupteten immerhin eine Mehrheit von einer Stimme gegenüber dem bürgerlichen Lager. Ab April gab es keine Kommunisten, seit dem 19. Mai 1933 auch keine Sozialdemokraten mehr im Stadtparlament (Claus Stäcker, Wahlen und Volksabstimmungen in der Stadt Wurzen von 1919 bis 1933, 1989, Typoskript im Archiv Stadtchronik Wurzen).

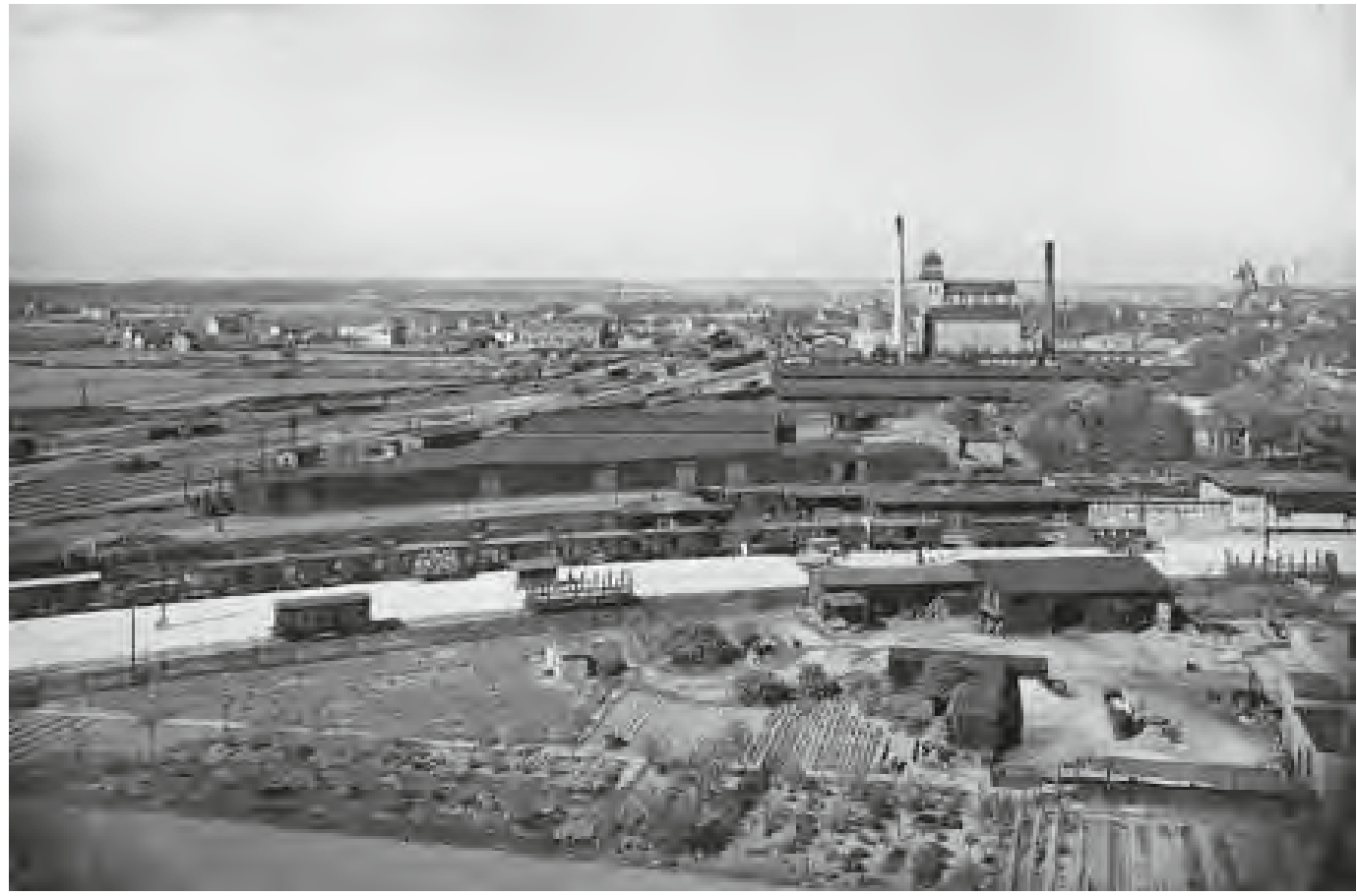

(der „Bürgerausschuss“ der Liberalen und Deutschnationalen 11, ASPD 2, USPD 8). Albert Kuntz wurde, für Sachsen damals einmalig, als Kommunist (unbesoldeter) Stadtrat. Die Nachkriegsjahre hatten unterdessen Wurzen wieder im Äußeren stark verändert. Die Mühlenwerke, 1917 vollständig ausgebrannt, gaben durch ihre wuchtigen Beton-Neubauten seit 1925 der Stadt eine völlig neue Ansicht. Ihnen war seit 1919 ein ganzer alter Stadtteil die Bleiche in der Muldenaue - zum Opfer gefallen. Gleichzeitig verschwand der Mühlgraben weitgehend durch den Bau eines Betriebskanals für das Wasserkraftwerk Canitz, und die Wurzener Teppichfabrik erwarb große Teile des alten „Kuhwerders“ in der angrenzenden Muldenaue für ihren Erweiterungsbau. Als Notstandsarbeit wurde nach dem Krieg die Eisenbahnverbindung nach Eilenburg fertig gebaut.

Die Stadt war 1919 entmilitarisiert worden; das Mannschaftsgebäude der Infanteriekaserne ließ die Stadtverwaltung bis 1929 schrittweise zum Stadthaus umbauen, und die Artilleriekaserne am Stadtpark diente bis 1935 als Wohn- und Gewerbegebiet.

Am 1. April 1924 - die politischen und wirtschaftlichen Verhältnisse hatten sich wieder einigermaßen stabilisiert - wurde Wurzen als kreisfreie Stadt aus der Amtshauptmannschaft Grimma ausgegliedert. ${ }^{53}$ Nach den Kommunalwahlen im November 1926 kam es zum ersten Mal zu einer linken „Großen Koalition“ in der Stadt: SPD und KPD einigten sich auf einen gemeinsamen Bürgermeisterkandidaten.
Unter dem sozialdemokratischen Ersten Bürgermeister Georg Boock (1891-1961) ${ }^{54}$ konnte die Linksmehrheit eine Reihe von sozialen Maßnahmen in Angriff nehmen. Der Wohnungsbau wurde angekurbelt, vor allem im Norden der Stadt. Es entstanden die Gebäude der Ortskrankenkasse oder das Sport- und Gewerkschaftsheim.

Aber auch linksorientierte Kommunalpolitik blieb den Zwängen der Zeit und den gesamtwirtschaftlichen Entwicklungen unterworfen, auch Notstandsarbeiten konnten die Auswirkungen der Weltwirtschaftskrise nicht bannen. Am 31. Januar 1932 wurden in Wurzen zwei Drittel der Erwerbstätigen als Arbeitslose registriert. Die Stadt war hoch verschuldet. Das und die zunehmenden Differenzen zwischen Sozialdemokraten und Kommunisten erleichterten die Demagogie der Nationalsozialisten. Diese schränkten nach ihrer Machtübernahme $1933^{55}$ die Selbstverwaltung der Stadt Schritt für Schritt ein. Das Rathaus wurde zum „Braunen Haus“ der SA. Zahlreiche Straßen erhielten in nationalsozialistischem Sinne neue Namen, vorhandene Einrichtungen wurden umfunktioniert (Gewerkschaftshaus, Wohnungsbaugenossenschaft) oder später liquidiert (Konsum-Genossenschaft) und das gesamte gesellschaftliche Leben gleichgeschaltet. Das Baugeschehen kam bald zum Erliegen, wenn auch einzelne Objekte noch zu Ende geführt wurden und die "Flugplatzsiedlung“ ein neues Siedlungsprogramm demonstrieren sollte. Etliche Wurzener - vor allem Kommunisten und Sozialdemokraten - verschwanden 


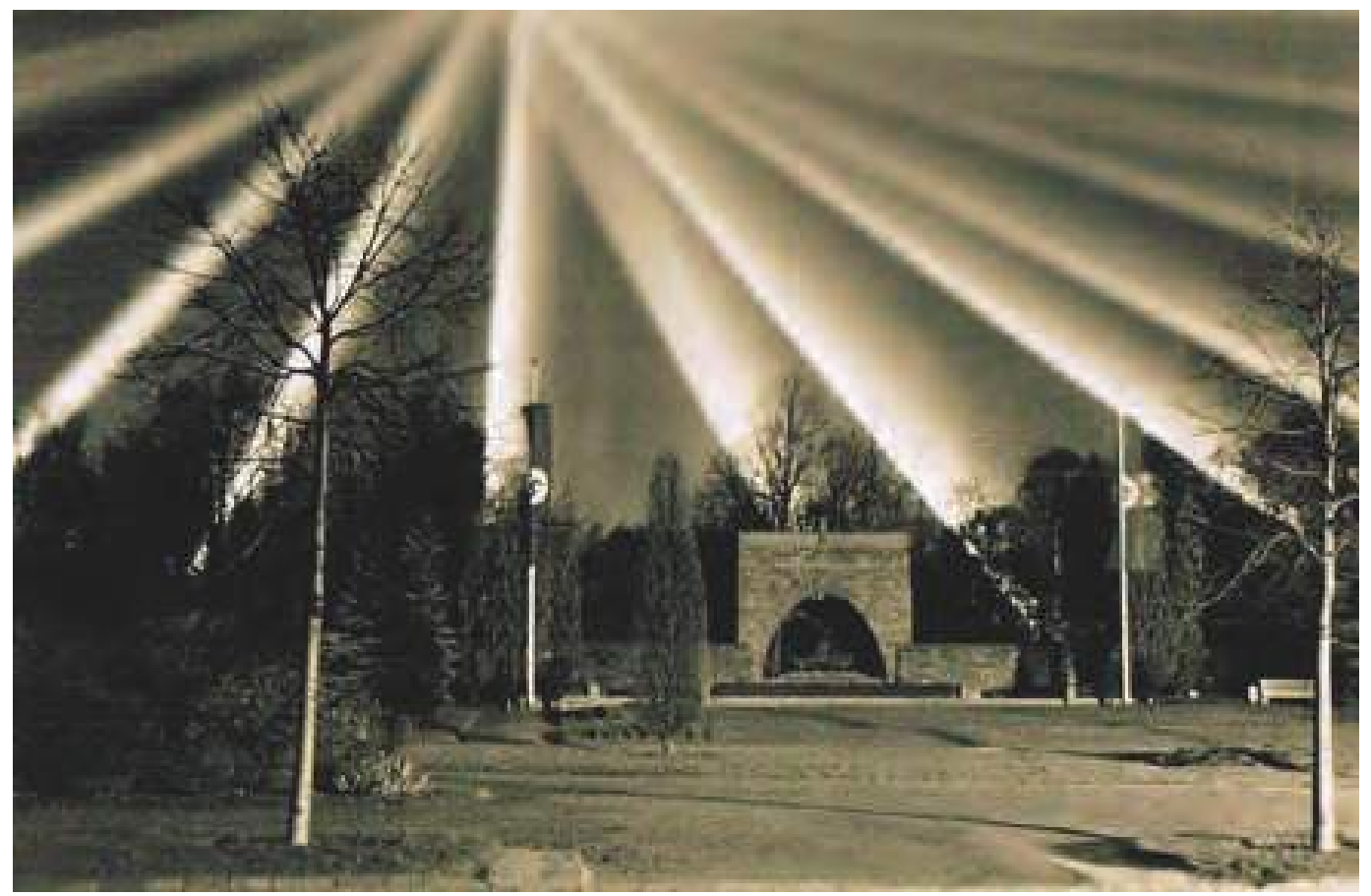

in Zuchthäusern und Konzentrationslagern. Die wenigen jüdischen Familien der Stadt wurden bis 1938 aus der Stadt vertrieben, die zurückgebliebenen 1942 zur Vernichtung deportiert.

1935 zog ein Flak-Regiment in die ehemalige Artilleriekaserne ein, damit begann die Remilitarisierung der Stadt und ihres öffentlichen Lebens, das ab 1936 mehr und mehr der Kriegsvorbereitung unterworfen wurde. Am 4. September 1939 fiel der erste Wurzener im Zweiten Weltkrieg. Bis zum 25. Oktober 1945 beurkundete das Standesamt Wurzen 650 „Kriegssterbefälle“, und sechs Wurzener kehrten nicht aus Konzentrationslagern zurück.

Kampfhandlungen erreichten die Stadt am 20. Oktober 1943 unmittelbar. Bei einem ersten Bombenangriff auf den Norden der Stadt starb ein Wurzener, bis Kriegsende werden über 40 Opfer durch Luftangriffe gezählt. ${ }^{56}$ Der Zweite Weltkrieg endete für die Stadt am 24. April 1945, nachdem Widerstandsgruppen in der Bevölkerung das Schlimmste hatten verhüten können, die letzten Wehrmachtseinheiten abgezogen waren und der Oberbürgermeister Dr. Armin Graebert (1898-1947) ${ }^{57}$ die Stadt an die Amerikaner übergeben hatte. ${ }^{58}$

\section{Einbeziehung in den sowjetischen Machtbereich. Aufbruch in den Sozialismus}

Mit der Besetzung Wurzens durch die Rote Armee am 5. Mai 1945 - die Amerikaner hatten sich in der Nacht zuvor auf das westliche
Mulde-Ufer zurückgezogen - begann ein völlig neues Kapitel in der langen Geschichte der Stadt. Bis zum Februar 1993, nahezu ein halbes Jahrhundert, sollte das fremde Militär die Stadt besetzt halten und vor allem ihren Norden, rund um die ehemalige Artilleriekaserne, und die Fluren bis hin zum Spitzberg bei Lüptitz in fremder und eigenwilliger Weise prägen.

Wurzen selbst hatte wenig Schaden im Krieg erlitten. Aber im April 1945 waren sämtliche Muldenbrücken gesprengt worden, seitdem war die Stadt immer wieder ohne Strom, Gas und Trinkwasser. An der Mulde stauten sich Tausende von Flüchtlingen, Vertriebenen, Fremd- und Zwangsarbeitern, ehemaligen Kriegsgefangenen sowie befreiten Häftlingen. ${ }^{59}$ Es kam zu Plünderungen und Übergriffen sowie zu Inhaftierungen. Bis Februar 1946 gingen insgesamt 313.700 Flüchtlinge und Vertriebene durch die Wurzener Lager.

Die Recht setzende und kontrollierende Tätigkeit der sowjetischen Militärbehörden schaffte nach und nach Rahmen und Grenzen für die neu eingesetzten Verwaltungsorgane. In ihnen wirkten vor allem Kommunisten und Sozialdemokraten, die teils erst aus den Zuchthäusern und KZs zurückgekehrt waren, dem Widerstand angehört hatten und der Besatzungsmacht am wenigsten kompromittiert erschienen. Alle NSDAP-Mitglieder wurden ab Mitte Mai aus ihren Ämtern entfernt. Der Entnazifizierung unterlagen vor allem ehemalige Zellen- und Blockleiter sowie die Polizeibeamten. 270 Personen wurden durch die sowjetischen Behörden interniert, bis März 1946 waren von
Illumination des Denkmals für die Gefallenen des Ersten Weltkriegs durch Flakscheinwerfer, 1938
56 Volker Engelhardt, Wurzener Kriegschronik (1939-1944), Typoskript im Kulturgeschichtlichen Museum Wurzen.

57 Dr. Armin Graebert, der Schwiegersohn des Bodenreformers Adolf Damaschke, stammte aus Berlin und war vor seiner Wurzener Amtszeit (1938-1945) Kämmerer in Weimar gewesen. Er starb in einem Lager der sowjetischen Besatzungsmacht.

58 Richard Klinkhardt, Die Ka pitulation von Wurzen am 24 April. In: Grenzfluss Mulde. Kriegsende 1945 in Nordsachsen (herausgegeben von Adolf Böhm und Wolfgang Ebert), Beucha 2005; Armin Graebert, Kurze Notizen für spätere Aufzeichnungen (Mai 1945), Typoskript im Kulturgeschichtlichen Museum Wurzen.

59 Richard Klinkhardt, Die Opfer des Todesmarsches durch Wurzen im April 1945. In: Grenzfluss Mulde, a.a.O., S. 49-52. 
Wohnungsbau in der Lüptitzer Straße, um 1960 ihnen bereits 36 verstorben. Auch Oberbürgermeister Dr. Graebert, dem die Stadt den entscheidenden Teil ihrer Rettung am Kriegsende verdankte, kehrte nicht wieder nach Wurzen zurück. Die Tatsache, dass nach Kriegsende namhafte SPD-Mitglieder wie Georg Boock oder Otto Schunke der KPD beitraten, verschaffte letzterer in Wurzen ein Gewicht, das sie nie hatte, und bereitete den Weg vor in die Vereinigung beider Parteien zur SED im April 1946. Nach der nationalsozialistischen Gewaltherrschaft und dem zerstörerischen Krieg sollte grundsätzlich mit der belastenden Vergangenheit gebrochen und die verhängnisvolle Spaltung der linken Parteien überwunden werden. Die „Machtfrage“, in der Novemberrevolution 1918 nach russischem Vorbild zum ersten Mal gestellt, wurde somit unter sowjetischer Vormundschaft entschieden. Die im Sommer 1945 entstandenen bürgerlichen Parteien CDU und LDPD wurden dieser neuen Entwicklung unterworfen, manche ihrer Mitglieder engagierten sich auch zunehmend bei der „,antifaschistischen Umwälzung", die durch die Schulreform und Bodenreform im Oktober 1945 und die Enteignung der größeren Industriebetriebe 1946 auch eine Neugestaltung der Macht- und Besitzverhältnisse - zunehmend nach sowjetischem Vorbild - bedeutete. Die Schaffung von „Volkseigenen“ Betrieben bis 1948 signalisierte bereits den grundsätzlichen Wandel in den Besitz- und Produktionsverhältnissen nach sowjetischem Muster. Die Etablierung eines Staatssozialismus ging einher

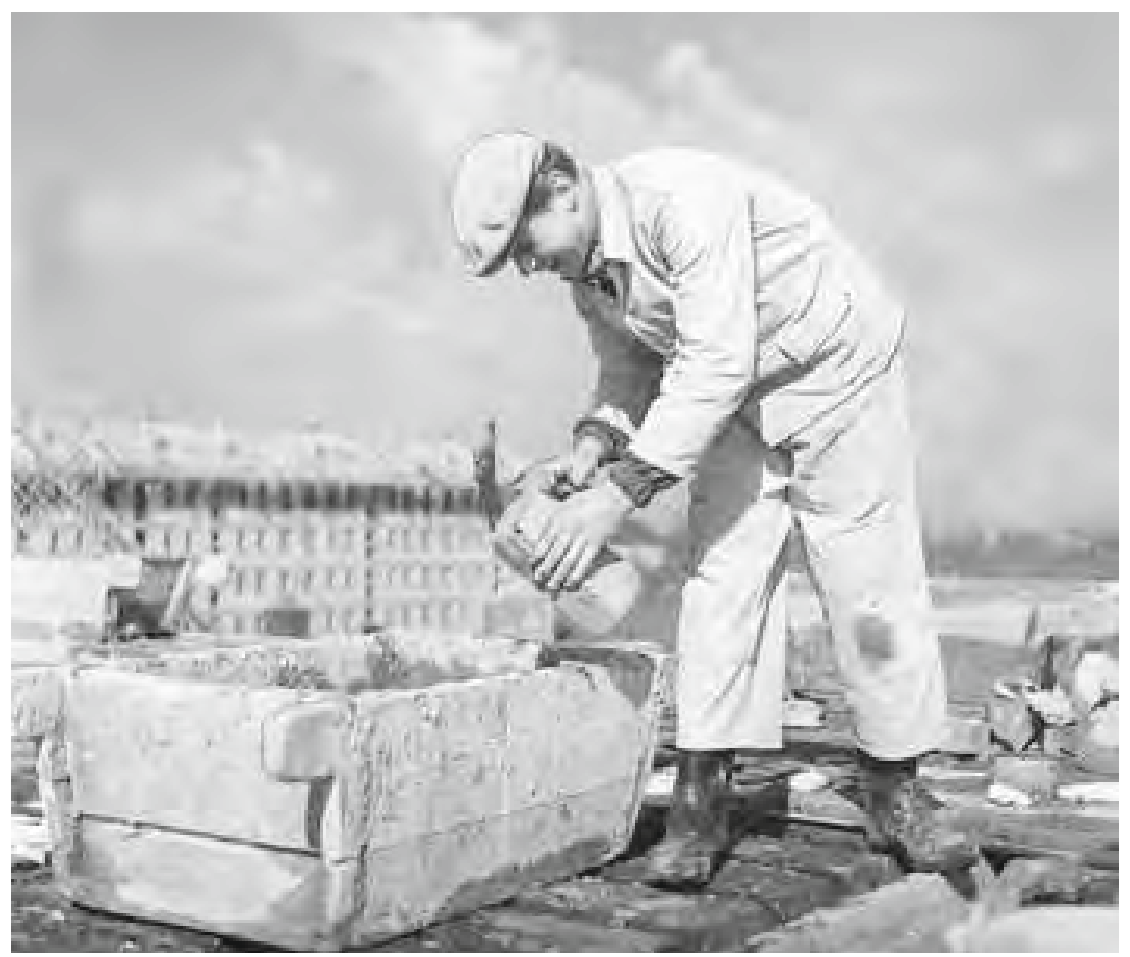

mit der oft ge-waltsamen Verdrängung der alten Eliten, die entweder die Stadt in Richtung Westdeutschland verließen oder, nachdem sie ihren bisherigen Einfluss verloren hatten, sich mehr oder weniger unterordneten oder abschotteten. Die Gründung der DDR 1949 war nur der äußerliche Abschluss dieser grundlegenden gesellschaftlichen Umgestaltungen unter dem Besatzungsregime, dessen sichtbare Anwesenheit am nördlichen Stadtrand fast 48 Jahre andauern sollte.

Durch die Verwaltungsreform 1952 erhielt Wurzen den Status einer Kreisstadt im Bezirk Leipzig. Die Verwaltungsreform schuf eine wichtige Voraussetzung für die in Angriff genommene sozialistische, zentralistisch geleitete Planwirtschaft. Der Rhythmus der Parteitage der SED und der Inhalt ihrer Festlegungen bestimmten damit immer mehr den Pulsschlag der Stadt, ihr wirtschaftliches, soziales und kulturelles Gepräge sowie das Leben ihrer Bewohner.

Obwohl nur wenige größere Betriebe die wirtschaftlichen Grundlagen der Stadt erweiterten (z.B. Baukombinat, Getreidewirtschaft, Motorenwerk), wurde die Wurzener Industrie seit den 1950er Jahren leistungsfähiger und exportintensiver. Die Kombinatsbildung in der DDR erfasste nach 1960 auch die Betriebe der Stadt, allerdings erhielt kein wichtiges Kombinat der DDR-Volkswirtschaft seinen Sitz in Wurzen, was die Bedeutung der Stadt innerhalb des Systems der Planung und Leitung der DDRVolkswirtschaft stark minderte. Die Infrastruktur wurde in dieser Zeit noch einmal den Bedürfnissen und technischen Möglichkeiten angepasst (Modernisierung von Brücken und Straßen, Ausbau der Kläranlage, der Wasserversorgung und Entwässerung, Elektrifizierung der Eisenbahn, S-Bahnanschluss nach Leipzig). Damit ist zwar eine intensivere Nutzung des Territoriums möglich, aber die zunehmende Zentralisierung der Planung und Leitung ließ - bürgerfern - ganze Bereiche des Wirtschaftslebens verkümmern oder verschwinden. Mittelständige Betriebe wurden in Volkseigentum überführt, Dienstleistungen und Versorgungsleistungen konnten immer weniger den Bedarf befriedigen. Bäcker, Fleischer oder Gaststätten gingen in ihrer Zahl stark zurück. Umweltproblemen standen die Behörden meist hilflos gegenüber.

Äußerlich am besten sichtbar wurde die Verwandlung Wurzens unter sozialistischem Vorzeichen im Baugeschehen. Noch nie wurde in der Stadt so viel an Wohnungen gebaut wie in den vier Jahrzehnten der DDR. Im Zuge einer rationelleren Nutzung der Stadtflur schlossen 


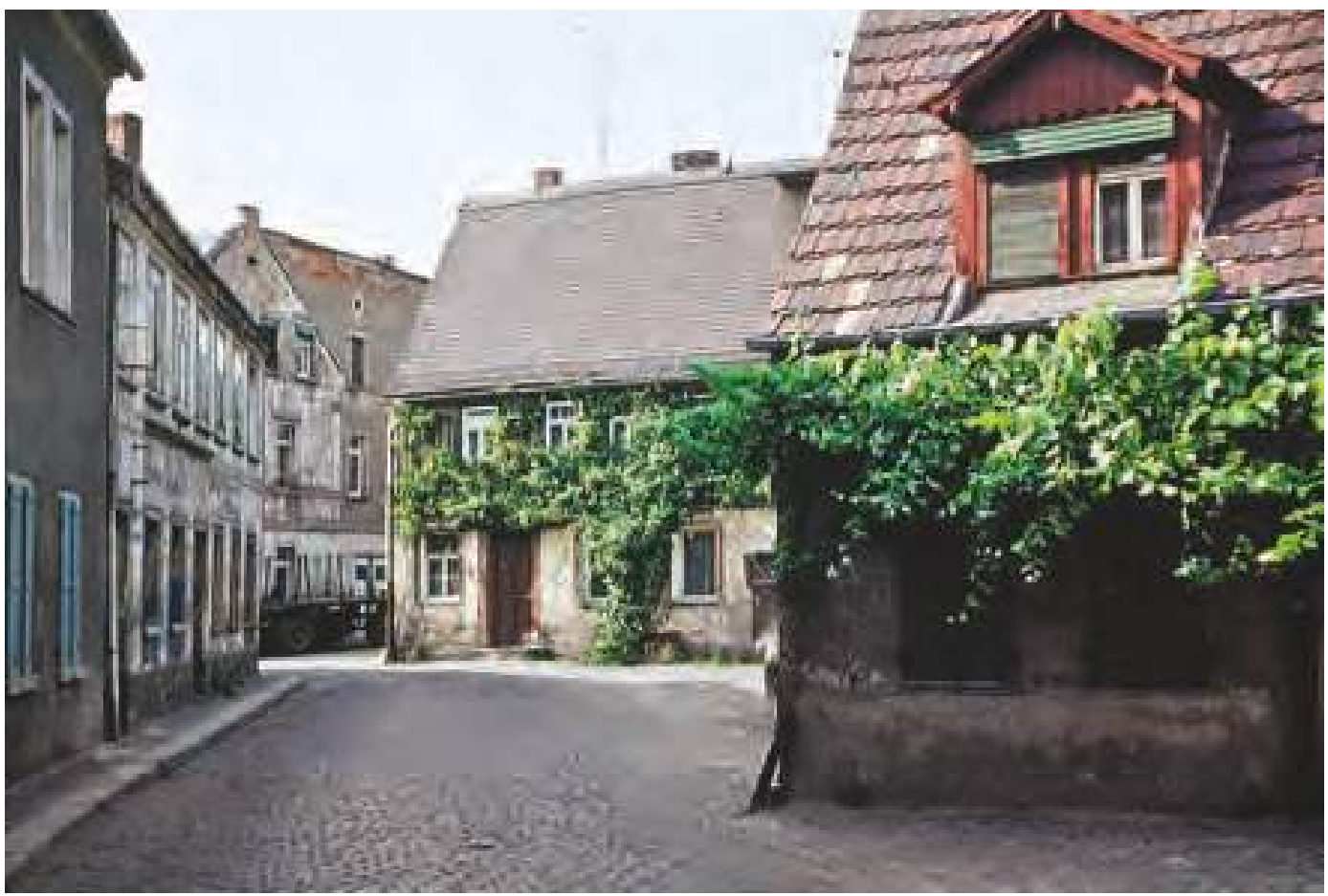

zahlreiche „Initiativbauten“ Wurzener Betriebe noch vorhandene Baulücken, musste seit 1982 ein Heizwerk entstehen, eine Voraussetzung dafür, dass am nördlichen Stadtrand ab 1984 in knapp 1.000 Tagen fast 1.000 Wohnungen im Plattenbaukomplex gebaut werden konnten. Kinderkrippen und -gärten, eine Schule und zwei Altenwohnheime kamen im Laufe der Jahre hinzu. ${ }^{60}$

Das historische Stadtzentrum und die städtische Infrastruktur mussten dafür einen hohen Preis zahlen. Viele Gebäude verfielen und wurden unbewohnbar, besonders baufällige Häuser verschwanden, die Abrissflächen wurden nur selten wieder bebaut. Allein der Marktbereich erlebte mit hohem Aufwand eine Erneuerung. Straßen, Wasserversorgung, Abwasserbehandlung und die Fragen nach vertretbaren Heizmedien und andere Probleme machten Rat und Bürgerschaft immer mehr Sorgen. Mittel dafür standen der Stadt kaum in erforderlichem Maße zur Verfügung; Betriebe, die Abhilfe hätten schaffen können, fehlten. Der für planwirtschaftliche Bedingungen typische Streit um zugeteilte „Kapazitäten und Bilanzen“ zwischen den Entscheidungsebenen zermürbte und deklassierte vor allem die Entscheidungsträger vor Ort und disqualifizierte sie zunehmend in den Augen der Bürger.

40 Jahre nach Gründung der DDR lebten in Wurzen noch 18.898 Einwohner (1972 waren es 24.356 gewesen), über die Hälfte von ihnen war erst in den letzten vier Jahrzehnten geboren worden. Aber mehr und mehr verließen die jungen Bürger die Stadt, weil es ihnen schwer fiel oder gemacht worden war, sich mit ihr zu identifizieren.

\section{Ausbruch aus Stagnation und Vormundschaft. Die friedliche Revolution 1989/90}

Schlangestehen gehörte Jahrzehnte lang zum realsozialistischen Alltag. Am 10. November 1989, einem Freitag und damit Werktag, standen die Menschen seit dem frühen Morgen vor dem Wurzener Schloss an, mehrreihig hintereinander über den Amtshof, durch die Domgasse bis zur Stadtapotheke am Markt: Sie holten sich bei der Volkspolizei ihr Visum in den Reisepass oder Personalausweis. Die Mauer war in der Nacht zuvor gefallen, die Menschen brachen aus aus Jahrzehnte langen Zwängen und Bevormundungen, aus Unmut und Verdrossenheit.

Widerstand gegen die Vormundschaftsanmaßung einer fadenscheinig legitimierten und immer mehr vergreisenden Staatspartei war in den vergangenen Jahren ohne Chancen gewesen. Konsequente Kritik an den bestehenden Verhältnissen führte den Kritiker letztendlich in die Fänge der Machtorgane, ins gesellschaftliche Abseits und nach draußen; so hatte die Anpassung immer mehr Gesichter bekommen. Die zunehmende, aber stets geheim gehaltene Zahl der Ausreiseanträge signalisierte schon lange das verdrängte Unbehagen, die Resignation, den inneren Bruch vieler mit dem beste-
Blick in die Altstadt mit baufälligen Häusern am Jacobsplatz, 1982

Foto: Wolfgang Ebert
60 Wolfgang Ebert, Ein Viertel der Wurzener zog um. Zur Vergangenheit und Gegenwart von Wurzen-Nord. In: Der Rundblick 2/1986 S. 82-86. 
Menschenschlange in der Domgasse am 10. November 1989 Foto: Wolfgang Ebert

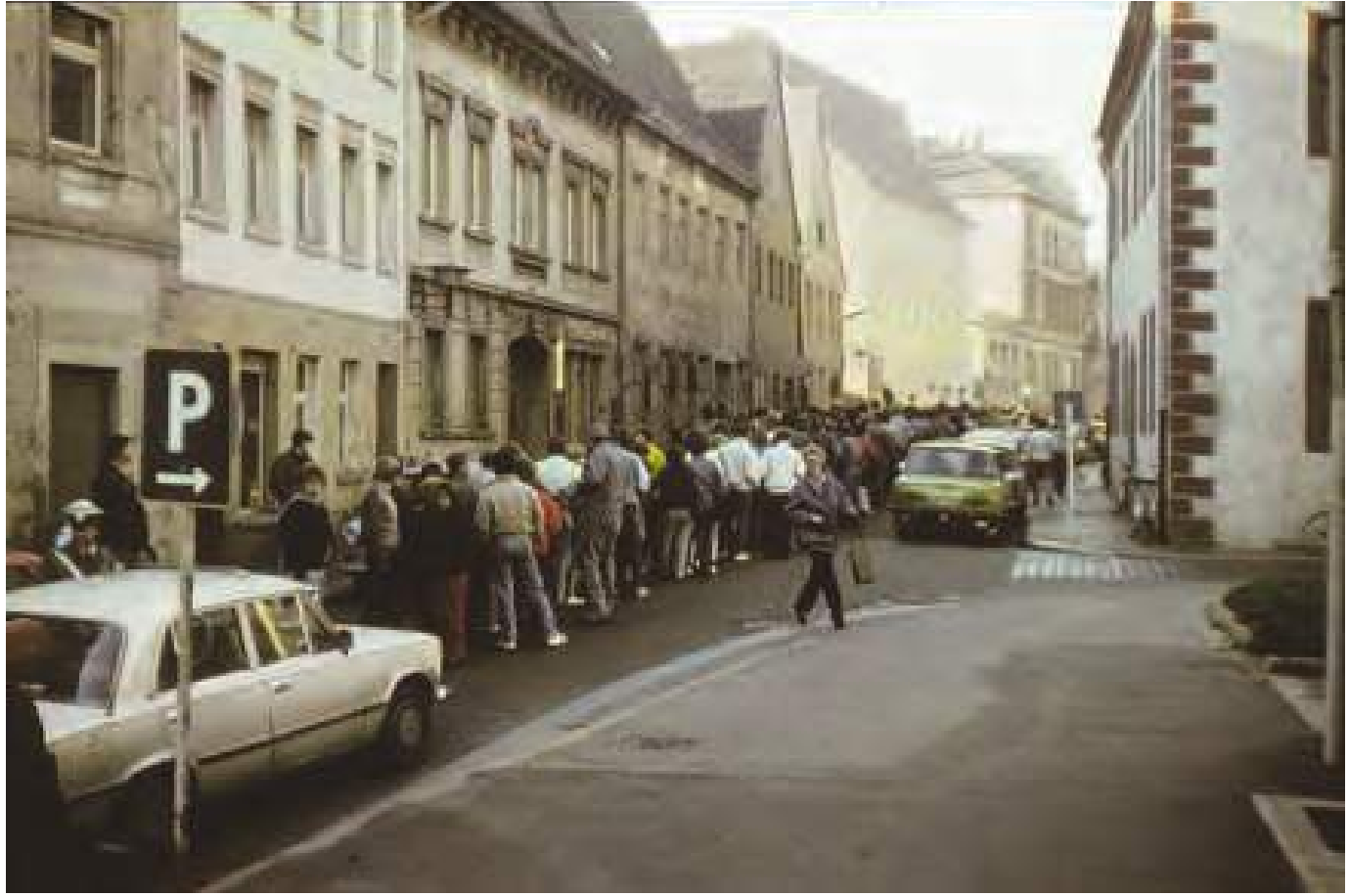

henden politischen System. Nach dem Mauerfall kam es nunmehr regelrecht zu einem Exodus. Das war nur ein begleitendes Moment der gesamtgesellschaftlichen Krise, die im Sommer und Herbst 1989 sichtbar kulminiert.

Bereits vor den Gemeindewahlen im Mai 1989 hatte man von Seiten der Staatsorgane ernste Bedenken: viele Bürger hofften, durch Abstimmungsverweigerung oder das Stimmen gegen die seit 1949 üblichen Einheitslisten Zeichen setzen zu können. Noch nie wurden so oft die Sonderwahllokale aufgesucht. Die Unzufriedenheit war allgemein: Der Verfall der Wurzener Innenstadt, ungelöste Umweltprobleme, ständige Versorgungsengpässe, oft nicht mehr akzeptable Arbeits- und Lebensbedingungen, Wohnungsknappheit, die Arroganz vieler Funktionäre, deren Ignoranz gegenüber Bürgerwillen und -begehren, die Reglementierungen des Einzelnen, dazu die zunehmend lächerliche Propaganda der SED und der übrigen Blockparteien in den Medien ließen Volk und Staat fühlbar miteinander brechen.

Laut offiziellem Wahlergebnis stimmten aber am 7. Mai 1989 nur etwa 2,5\% der Wurzener gegen die gewohnte Einheitsliste. Vorher waren noch etliche Ausreisewillige ausgebürgert worden. Im Sommer suchten sich die Menschen selbst ihren Weg über Ungarn und die Tschechoslowakei. Die Friedensgebete in der Leipziger Nikolaikirche zogen bereits im Sommer auch Wurzener Bürger an. Der 7. Oktober 1989, der mit propagandistischem
Großeinsatz begangene 40. Jahrestag der DDR-Gründung, verlief zwar in Wurzen selbst ohne große Zwischenfälle bei Präsenz aller verfügbaren Sicherheitsorgane. Aber zwei Tage später waren auch viele Wurzener nicht mehr zu halten - sie gehörten zu den 70.000 , die auf dem Ring in Leipzig gegen SED und für Reformen demonstrierten.

Seit dem 16. Oktober 1989 erklang der Ruf "Wir sind das Volk" auch in den Wurzener Straßen. Die Friedensgebete im Dom, später auch in den anderen Kirchen, wurden zum Ausgangspunkt für die Montagsdemonstrationen. Sie kannten zunächst nur zwei Ziele: die SED-Kreisleitung am Stadtpark und die Dienststelle der Staatssicherheit am Dehnitzer Weg (heute Carl-Magirius-Straße). Langsam setzten „Dialoge“ zwischen Staatsorganen und Bevölkerung die Auseinandersetzung fort, sie offenbarten nunmehr sichtbar den Bruch der Menschen mit dem bisherigen Herrschaftssystem. Die Destruktion der staatlichen Gewalt begann. Nicht nur die Staatssicherheit wurde aufgelöst, ihr Gebäude am 5. Dezember 1989 besetzt und versiegelt, die Räte der Stadt und vor allem des Kreises wurden attackiert, Untersuchungsausschüsse mussten gebildet werden, Bürgerinitiativen und -komitees schalteten sich aktiv in die Ereignisse ein. Neue politische Gruppierungen traten an die Öffentlichkeit: im September schon das Neue Forum, im Dezember und Januar auch neue Parteien wie der Demokratische Aufbruch oder die wieder gegründete SPD. Die alten Parteien mussten 


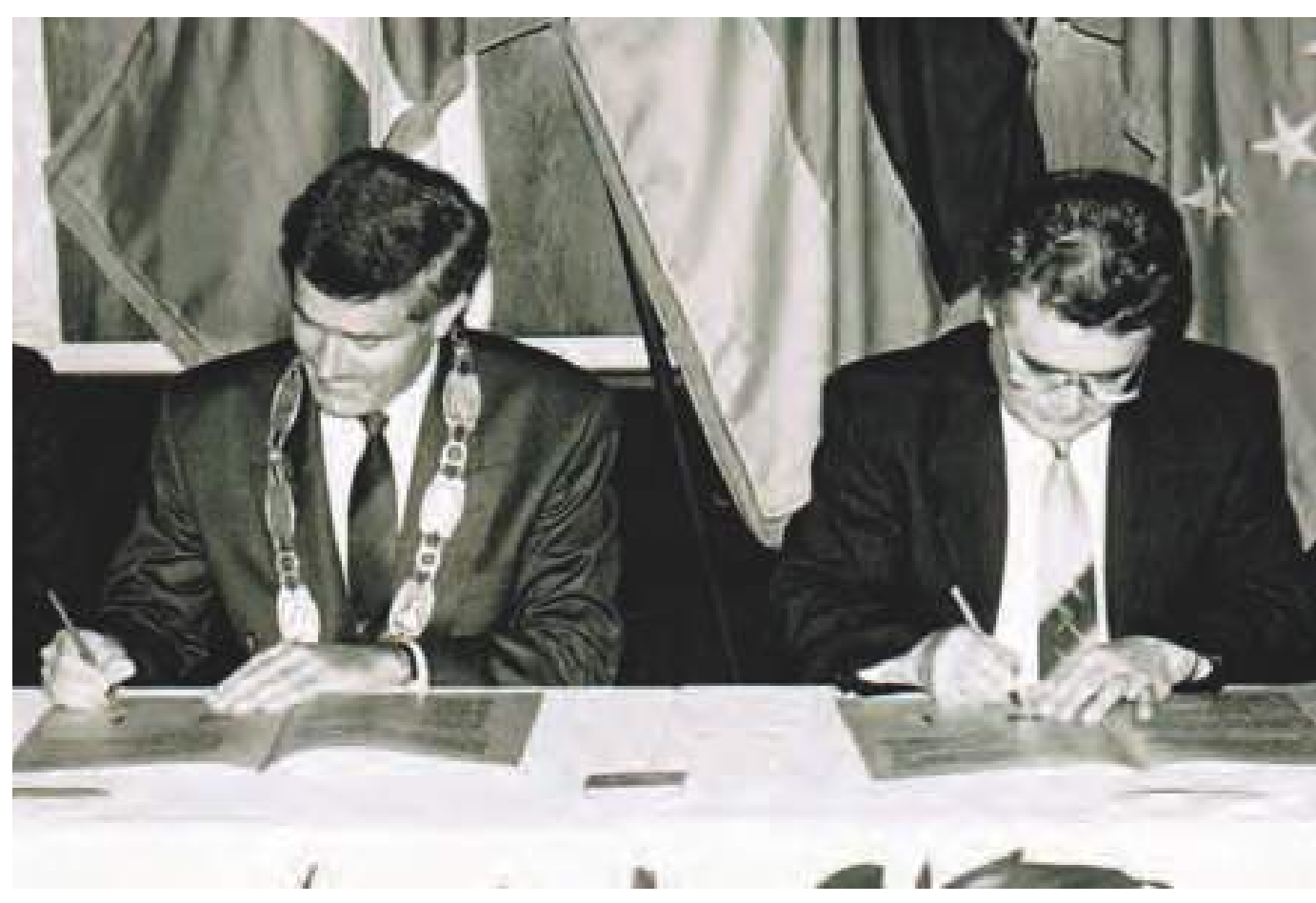

sich personell und programmatisch schmerzlich strecken, um ihren Wandel von Mitläufern und Mithelfern zu Umgestaltern glaubhaft $\mathrm{zu}$ machen. Seit Februar 1990 versammelten sich alle Gruppierungen am Runden Tisch, den in Wurzen Superintendent Horst Schulze ${ }^{61}$ leitete. Durch ihn ließ sich mancher Konsens zwischen den bisherigen Amtsträgern und den oppositionellen Gruppen finden und das gesellschaftliche Chaos bannen.

Die Montagsdemos verwandelten sich unversehens in Wahlkampfveranstaltungen. Auf dem Wurzener Markt, der im Januar seinen alten Name wieder zurückerhalten hatte ${ }^{62}$, wurden die schwarz-rot-goldenen oder weißgrünen Banner geschwenkt. Die Versammlungen am Ringelnatzbrunnen nahmen an Hysterie und Aufwand zu. Am 12. März 1990 bemühte sich sogar Lothar Späth, der damalige baden-württembergische Ministerpräsident, auf den Balkon des Rathauses, um zu den zahlreich Versammelten zu sprechen. Am Sonntag darauf schlossen die Bürger der Stadt bei den ersten freien Wahlen zur Volkskammer der DDR auf ihre Weise ab mit der Geschichte des Staatssozialismus: Im ehemals „roten“ Wurzen wählten nach über 40 Jahren SED-Vorherrschaft mehr als die Hälfte der Wahlberechtigten die um die CDU versammelte „Allianz für Deutschland“, nur $17 \%$ der Stimmen erhielt die erwartungsvolle SPD, $12 \%$ die SED-Nachfolgepartei PDS. ${ }^{63}$

Nach den Kommunalwahlen am 6. Mai 1990 zogen 14 Christdemokraten, je 7 Liberale und Sozialdemokraten, 5 Abgeordnete der PDS, 2 der Grünen Partei und je ein Vertreter der DSU, des Demokratischen Aufbruchs und des Neuen Forums in die Stadtverordnetenversammlung ein. Mit Anton Pausch (CDU, geb. 1938 in Ungarn $)^{64}$ bekam Wurzen zum ersten Mal seit der Reformation im 16. Jahrhundert einen katholischen Bürgermeister. Dr. Frank Heine (1942-1994), im Herbst und Winter Vorsitzender des Bürgerkomitees Wurzen und als parteiloser Spitzenkandidat auf der liberalen Liste, erhielt bei der Wahl mit Abstand die meisten Stimmen und wurde von den Stadtverordneten zum Vorsteher gewählt. Eine große Koalition aus den ehemaligen Allianzparteien, den Freien Demokraten, den Sozialdemokraten sowie dem Neuen Forum stellte sich Ende Mai 1990 den Erwartungen der Bevölkerung, den drängenden Aufgaben des Tages, den Vorbereitungen für die Wirtschafts-, Währungs- und Sozialunion mit den Verpflichtungen, die aus den Traditionen und der langen Geschichte der Stadt erwuchsen.

\section{Rückkehr zur Geschichte und Eintritt ins postindustrielle Zeitalter}

Wohl kaum eine andere Nacht in der jüngeren deutschen Geschichte war emotional so beladen wie die vom 2. zum 3. Oktober 1990. Auf den Straßen und im Wurzener Dom lagen sich um Mitternacht Menschen in den Armen, waren ergriffen, jubelten, weinten. Um Mitternacht hörte das staatliche Gebilde endgültig dem westlichen Teil Deutschlands, aber auch
Unterzeichnung der Städtepartnerschaft mit Warstein am 3. Oktober 1990

611935 in Aue geboren, seit 1982 Pfarrer und Superintendent in Wurzen, seit 1982 Dechant des Domkapitels, 2009 i R., 2005 Ehrenbürger der Stadt Wurzen-

62 Seit den 1950er Jahren hieß er „Platz der Deutsch-sowjetischen Freundschaft".

63 Wolfgang Ebert, Mit vierzig ist der Berg erstiegen. In: Der Rundblick 2/1990, S. 86-89.

64 Wolfgang Ebert, Anton Pausch. Bürgermeister 1990-1997, Oberbürgermeister 1997-2001.In: Hansrainer Baum/Jürgen Schmidt, Von Schmidt zu Schmidt. Über Wurzener Bürgermeister 18322008, Wurzen o.J., S. 111-113. 
Pflanzung des ersten Baums im neuen Wurzener Stadtwald am 30. Oktober 1997 Foto: Wolfgang Ebert

65 Maschinenfabrik Wurzen (bis 1945 G.A. Schütz).

66 (Wurzener) Transportanlagen (früher G.F. Lieder GmbH)

67 www.wegweiser-kommune.de (abgerufen am 20.11.2014). auf zu bestehen, das die Lebensläufe auch der Wurzener über vier Jahrzehnte in besonderer Weise geprägt, am Ende bis zur Unerträglichkeit beengt hatte. Erwartungen und Befürchtungen lagen bei jedem, unabhängig von seiner politischen Grundhaltung, im Widerstreit, wurden zunächst nur mit einem Mantel weiten Jubels zugedeckt, der sich aus einem Aufatmen und dem allgemeinen Gefühl von Freiwerden ergab. Ein lähmender Druck schien hinweg genommen, der von Jahr zu Jahr schwerer über Stadt und Land und über jedem einzelnen gelegen hatte. warnten, was da geschehen sollte, und die helfen wollten bei dem, was unumgänglich geworden war.

Aber eine Mehrheit der Bürger wollte eben keine Milch mehr in Flaschen kaufen; ohne einheimischen Markt hatte somit die Wurzener Molkerei keine Chance mehr. Sie war einer der ersten größeren Betriebe der Stadt, der den aufzüngelnden Gesetzen des Marktes erlag. Was mochte einen alteingesessenen Fleischer plötzlich bewegen, sich Metzger zu nennen?

Das letzte Jahrzehnt im 20. Jahrhundert hat in Wurzen eine tief greifende Änderung der

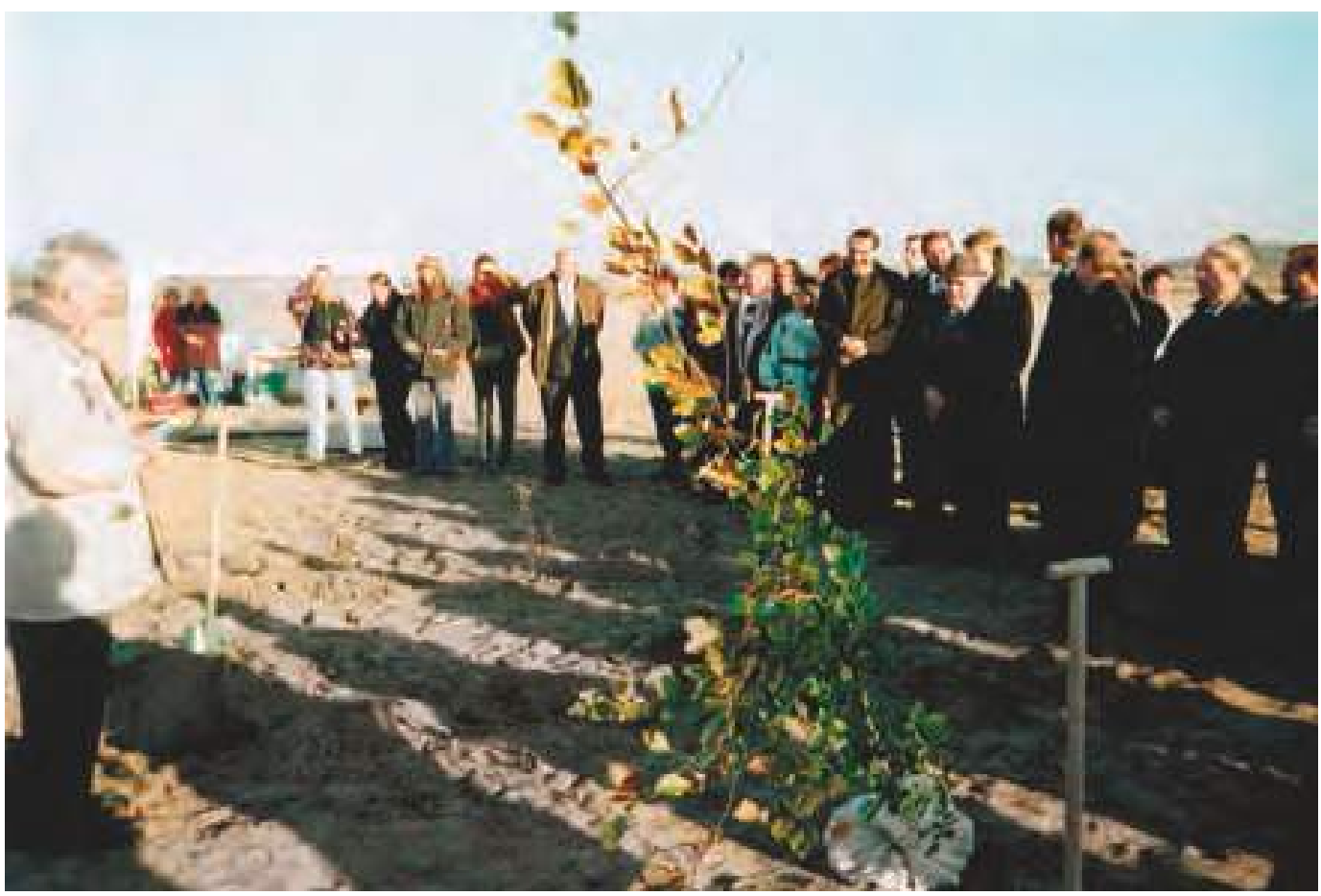

Dieses Freiwerden hatte aber dem aufmerksamen Beobachter schon sein Doppelgesicht gezeigt. Noch in der Einheitsnacht holen Jugendliche am Markt die Europafahne herunter und zerstören den Mast. Bombendrohungen waren in den vergangenen Monaten an die Adresse von Landratsamt, Krankenhaus und Schulen gegangen. So etwas hatte es bisher nicht gegeben. Die Menschen waren angekommen in der Welt, die sie nur aus den Medien kannten, jetzt waren sie ein Teil der ganzen Welt. Das überforderte sichtlich. Fremde Menschen tauchten in der Stadt auf: fliegende Händler von weither, die alltägliche Dinge, sogar normales Brot anboten und loswurden; Menschen, die Eigentum zurückforderten und damit manche Zukunftsplanung gefährdeten; findige und windige Immobilienkäufer auf der Suche nach Schnäppchen und dann Ausländer, die ihre Armut zeigten. Es kamen auch die Menschen, die vor all dem
Wirtschaftsstruktur bewirkt: Industriebetriebe, auf die die Stadt einmal stolz war, die ihren Bürgern Arbeit und Brot gaben, wie die Teppichfabrik, die MAFA ${ }^{65}$, die Wutra ${ }^{66}$, das Drahtseilwerk, auch das Motorenwerk, existieren nicht mehr. Ihrer traditionellen Märkte verlustig gegangen, oft vorschnell und halbherzig privatisiert, unterlagen sie auf den neuen Märkten, oder sie wurden von ihren Konkurrenten aufgekauft und stillgelegt. Davon zeugten lange die Industriebrachen im Süden und Nordosten der Stadt. Nur einzelne Betriebsteile oder stark verkleinerte Betriebe sind noch am Leben. Wasserglas, Filze, Kekse, Luftfilter und Transportanlagen kommen weiterhin aus Wurzen. Die Ansiedlung neuer Firmen oder die Erweiterung bereits vorhandener bleibt eine ständige Herausforderung. Manche Fabrikgebäude, zumal denkmalgeschützte in der Innenstadt, wurden und werden in Altenwohnheime umgebaut. Kein Bei- 


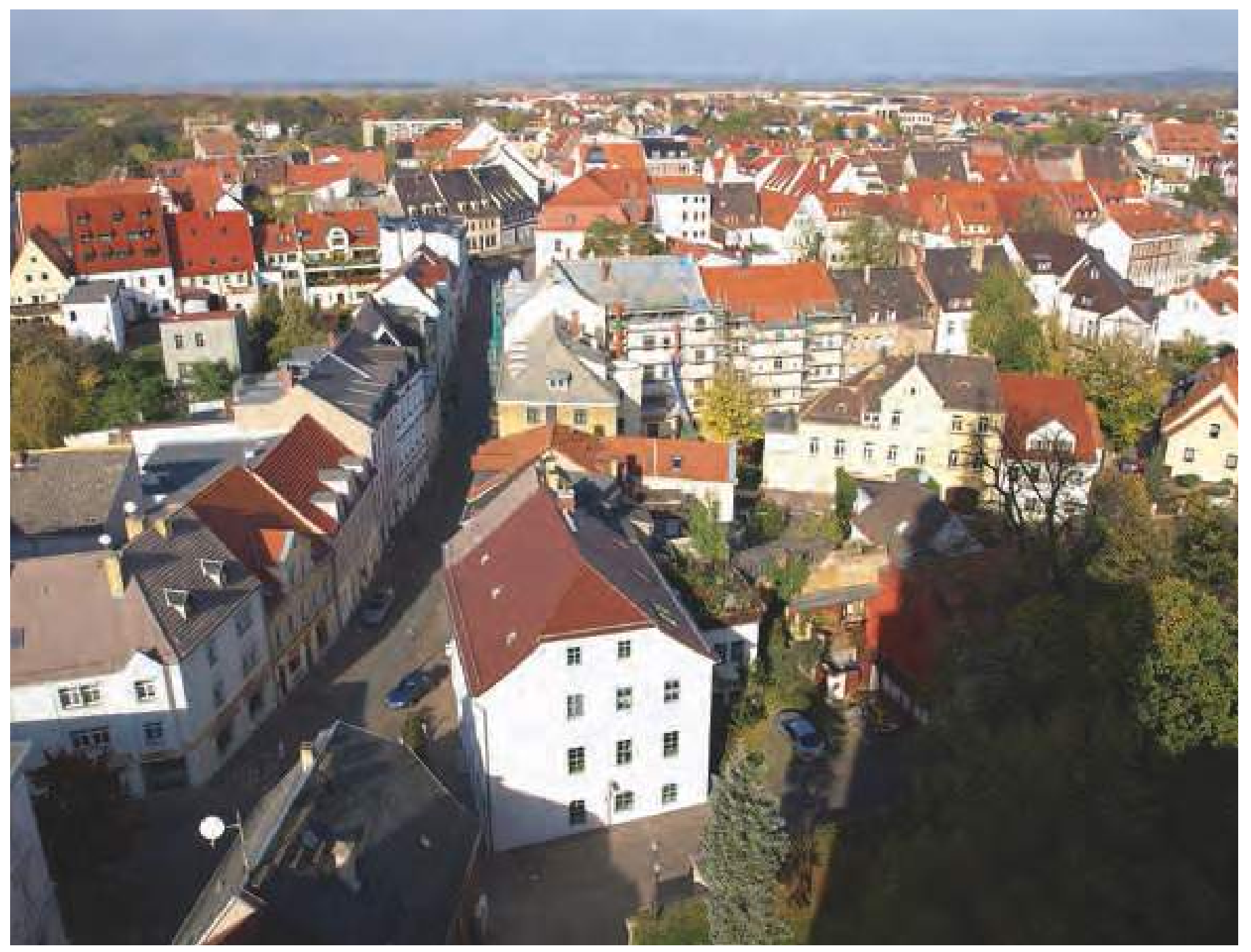

spiel kann besser die allgemeine Umwertung versinnbildlichen. Auf den neuen, überdimensionierten Gewerbegebieten am Nordrand der Stadt wartet man am Anfang des neuen Jahrhunderts aber weiterhin auf Unternehmen, die sich dort niederlassen und die Autohäuser, Supermärkte und Tankstellen, die nunmehr wie ein Ring die Stadt umgeben, mit produzierenden Gewerben ergänzen.

Vor diesem nicht ermunternden Hintergrund heben sich die Fortschritte in der Stadtsanierung und in der Erneuerung der Infrastruktur auffällig und beeindruckend ab. Noch nie in seiner Geschichte zeigte Wurzen ein so gefälliges und idyllisches Bild, wenn man sich ihm näherte oder wenn man das Stadtzentrum durchquerte. Nach der Jahrtausendwende sind ganze Straßenzüge in der Innenstadt wieder bewohnbar geworden, und am Stadtrand entstanden Eigenheimsiedlungen. Medien und Entsorgungseinrichtungen haben meist schon den modernsten Zuschnitt. Ruinöse Gebäude verschwinden nach und nach aus dem Stadtbild, und das alte Kasernengelände nördlich des Stadtparkes verwandelte sich Schritt für Schritt in einen Wohnpark. Die Stadt ist mehr durchgrünt als je zuvor.

Doch die Zeiten scheinen endgültig vorbei zu sein, in denen es in der Innenstadt einmal über 40 Bäcker, über 30 Fleischer, über 30 Gaststätten und viele kleine Läden für die Dinge des täglichen Bedarfs gegeben hat. Zunehmend stehen immer mehr Wohnungen und Geschäfte in der Stadt leer. Der Sog der nahen Großstadt Leipzig und die gute Verkehrsanbindung dorthin wirken sich nicht nur günstig aus. Schon seit der Mitte des 20. Jahrhunderts ist die Einwohnerzahl Wurzens rückläufig. Das Eigenheim auf dem Lande können sich manche leisten, andere verlassen die Stadt auf der Suche nach einem Arbeitsplatz. In der Stadt bleiben die Älteren zurück mit ihren Problemen, mit ihrer Lebensweise. Der Generationenkonflikt mischt sich deshalb in besonderer Weise in die ideologisierenden Auseinandersetzungen zwischen den politi-
Blick vom Turm der Wenceslaikirche in die Altstadt, 2008 Foto: Wolfgang Ebert 
schen Kräftegruppierungen in der Stadt, die ein Vierteljahrhundert nach der deutschen Wiedervereinigung die typische politische Landschaft aufweist, wie es in der Mehrzahl der bundesdeutschen Kleinstädte der Fall ist und die nur noch wenig an die Zeit des Aufbruchs von 1989/90 erinnert.

\section{Der letzte Stand der Dinge: Große Kreisstadt im Landkreis Leipzig}

Am 1. April 1997 erklärte die Sächsische Staatsregierung Wurzen zur Großen Kreisstadt. Die Realität hinter dem hochtrabenden Titel ist ganz anders beschaffen: Seit dem 1. August 1994 ist Wurzen keine Kreisstadt mehr. Der seit 1952 bestehende Kreis Wurzen ging bei der Gebietsreform im Muldentalkreis mit der Kreisstadt Grimma auf. Zwar wurden in Wurzen zum Ausgleich dafür zunächst eines der früheren drei sächsischen Ämter für ländliche Neuordnung angesiedelt und das Bundessortenamt weitergeführt. Aber nach der Integration des Muldentalkreises 2008 in den neu gebildeten Landkreis Leipzig setzte sich der in der Geschichte der Stadt bisher einmalige Abbau der zentralörtlichen Funktion für ihr historisch gewachsenes Umland fort (Wegfall des Amtsgerichts, der Landesversicherungsanstalt; weitere Reduzierung bei Behörden, so bei der Polizei). Im überarbeiteten Landesentwicklungsplan von 2003 wird das Mittelzentrum Wurzen auch nur noch als so genannter „Ergänzungsstandort im ländlichen Raum" eingestuft.

Gemäß der Demographie-Studie der Bertelsmann-Stiftung von 2012 gehört die Stadt heute $\mathrm{zu}$ den 264 „stark schrumpfenden Kommunen mit besonderem Anpassungsdruck $^{167}$, die fast alle in Ostdeutschland liegen. Die Einwohnerzahl sinkt immer noch beständig, auch obwohl Eingemeindungen in den letzten Jahren das Stadtgebiet vergrößerten. Dazu steigt das Durchschnittsalter und die Zahl der Single-Haushalte oder der ohne Kinder.

Die Stadt besitzt trotz aller Wendeverluste nach wie vor vielfältige Gewerbe- und Industriebetriebe, sie ist damit Arbeitsort für das Umland und auch eines seiner Versorgungszentren geblieben (Krankenhaus. Handelseinrichtungen), darüber hinaus ein wichtiger Schulstandort (Magnus-Gottfried-LichtwerAutor Gymnasium, Pestalozzi-Oberschule, drei Wolfgang Ebert Grundschulen, Berufliches Schulzentrum, Wurzen Förderschule, Musikschule, Volkshochschule).
Zwei neue Gewerbegebiete wurden seit 1993 am nördlichen Stadtrand erschlossen. Sie und das Gelände des früheren Motorenwerks, das zu einem Mittelstandszentrum ausgebaut wurde, sollen künftig verstärkt Gewerke und Gewerbe anziehen, die Wurzens Bedeutung als Gewerbe- und Dienstleistungszentrum für das Umland erhöhen.

Viel stärker, als es je zuvor zu beobachten war, ist die Stadt heute mit ihren kommunalen Interessen und Aktivitäten natürlich in Konkurrenz zu Nachbargemeinden geraten. Genauso sind die Dörfer und Städte der Umgebung durch ihre Kompetenzen, die sie in der Planwirtschaft niemals hatten, Konkurrenten für die Stadt, zum Beispiel als Wohn-, aber auch als Gewerbe- oder Schulstandorte. So muss die Stadt sich auch als Standort für möglichst zahlreiche Dienstleistungen sowie für vielfältige Kultur- und Sportangebote qualifizieren. Der Erhalt, die Sanierung und der Ausbau von Kultur- und Sportstätten sowie von Schulen und Vorschuleinrichtungen stehen deshalb zu Beginn des neuen Jahrhunderts erneut obenan.

Nach Ende des zweiten christlichen Jahrtausends, über dessen ganze Dauer sich die wechselvolle Geschichte der Stadt bisher erstreckte und in dem ihre Bewohner nicht nur einmal existenziell bedroht waren, befinden sich diese wieder in einer Bewährungssituation, deren Ende und Ausgang im Einzelnen noch nicht abzuschätzen sind. Erstmalig in der Geschichte der Stadt müssen die Bürger um etwas ringen, was bisher immer selbstverständlich war: Es geht in einer immer stärker durch Medien vermittelten und wahrgenommenen Wirklichkeit um Image und Attraktion, um ein gefälliges Gesamtbild, den guten Ruf von Ort und Leuten, was alles über Gebühr notwendig scheint auch für einen wirtschaftlichen und kulturellen Aufschwung und den Bestand in einer Welt ohne abschirmende Grenzen.

„Ein gutes Stück Sachsen“ ist seit 1992 die Image-Parole der Stadt, damals hat man sich mit großen Hoffnungen dafür entschieden. „Fabelhaftes Wurzen“ (in Erinnerung an den in Wurzen 1719 geborenen Fabeldichter Lichtwer) hatte nach der Jahrtausendwende dagegen keine Chance. Seit 1983 steht am Brunnenstock des Marktbrunnens, der dem ebenfalls in Wurzen geborenen Dichter Joachim Ringelnatz geweiht ist, dessen Ausspruch „Überall ist Wunderland“. Für den Tag der Sachsen 2015 wandelte die Wurzener Stadtverwaltung das Wort vielsagend zum Anspruch ab: „Hier ist Wunderland“. 